\title{
Antibiotic release controlled by sugarcane bagasse- based hydrogels as responsive carriers
}

\section{Kunni Yang}

Guangxi University

\section{Pingxiong Cai}

Beibu Gulf University

Yuanfeng Pan ( $\nabla$ panyf@gxu.edu.cn )

Guangxi University https://orcid.org/0000-0002-5002-5383

\section{Research Article}

Keywords: Sugarcane bagasse, Hydrogel, Dual-responsive, Controlled release

Posted Date: February 23rd, 2021

DOl: https://doi.org/10.21203/rs.3.rs-215920/v1

License: (c) (1) This work is licensed under a Creative Commons Attribution 4.0 International License. Read Full License 


\section{Antibiotic release controlled by sugarcane bagasse-based hydrogels}

\section{as responsive carriers}

Kunni Yang a , Pingxiong Cai ${ }^{b}$, Yuanfeng Pan ${ }^{a, *}$

${ }^{a}$ Guangxi Key Laboratory of Petrochemical Resource Processing and Process

Intensification Technology, School of Chemistry and Chemical Engineering, Guangxi

University, Nanning 530004 China.

${ }^{b}$ College of Petroleum and Chemical Engineering, Beibu Gulf University, Qinzhou, 535011 China.

*Corresponding author's E-mail addresses: panyf@gxu.edu.cn (Y. Pan)

Tel: +86-771-3236484 (Y. Pan); Fax: +86-771-3236484 (Y. Pan)

Abstract This work focuses on the transesterification of sugarcane bagasse cellulose (SBC) using tert-butyl acetoacetate (t-BAA) to obtain bagasse cellulose acetoacetate (BCAA), and the preparation of redox/pH dual-responsive hydrogels with cystamine dihydrochlorate (CYS). BCAA and cellulose hydrogels were comprehensively characterized with scanning electron microscopy (SEM), Fourier transform infrared (FTIR), nuclear magnetic resonance (NMR), solubility and water retention. The results showed that BCAA was soluble in DMSO, and the degree of substitution (DS) ranged between 0.77 and 1.70 , and the hydrogel had a certain water-retaining property. In addition, tetracycline hydrochloride ( $\mathrm{TH}$ ) was used as the model drug loaded in the hydrogel; and $\mathrm{TH}$ release can be manipulated or accelerated under reductive or weakly acidic conditions. According to the drug release kinetics analysis, suggested that the release mechanism of drug-loaded hydrogel was mainly driven by Fickian diffusion. The drug-loaded hydrogel also exhibited high antibacterial activity against Staphylococcus aureus (S. aureus) and Escherichia coli (E. coli). Therefore, the dual-responsive and drug-loaded hydrogels have great potential in the applications associated with biomedicine. 
32

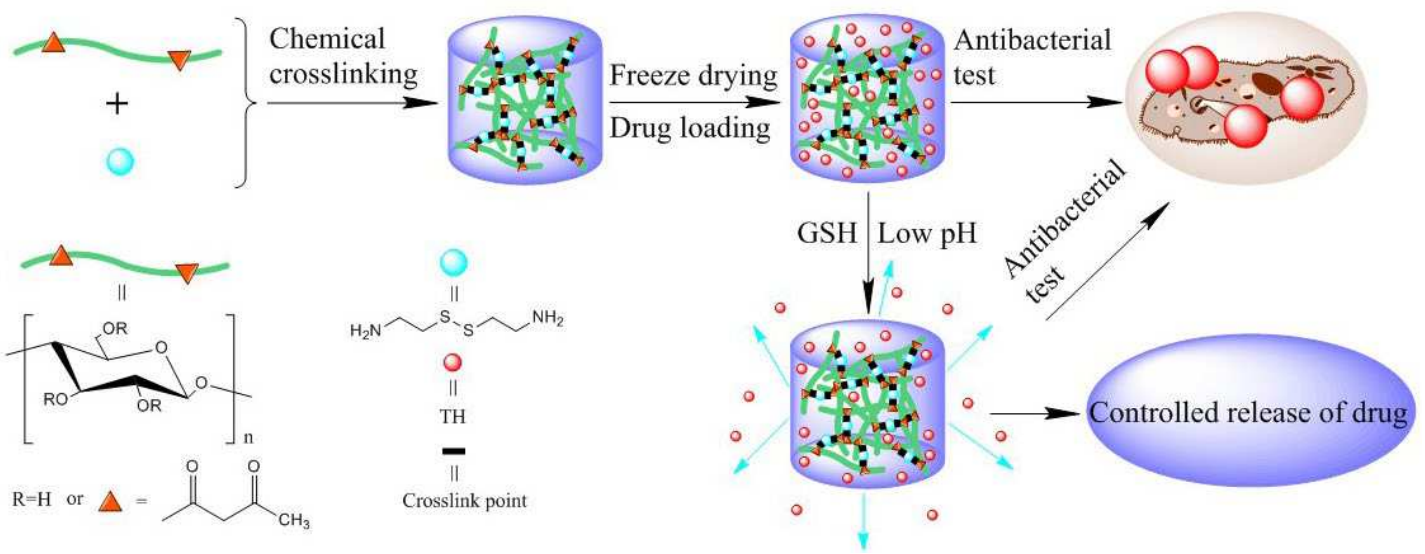

Keywords Sugarcane bagasse $\cdot$ Hydrogel $\cdot$ Dual-responsive $\cdot$ Controlled release

\section{Declarations}

\section{Funding}

This work was supported by the National Natural Science Foundation of China [grant number 22068006 \& 21306027] and the Dean Project of Guangxi Key Laboratory of Petrochemical Resource Processing and Process Intensification Technology [grant number 2019Z003].

\section{Competing interests}

The authors declare that they have no known competing financial interests that could have appeared to influence the work reported in this paper. All authors have given approval to the final version of the manuscript.

\section{Availability of data and material}

The raw/processed data required to reproduce these findings cannot be shared at this time as the data also forms part of an ongoing study.

\section{Code availability}

No code was involved in the work reported.

\section{Authors' contributions}

The manuscript was prepared through contributions of all authors. Kunni Yang: Methodology, Data curation and Writing-Original draft preparation. Pingxiong Cai: 
Formal analysis and Resources preparation. Yuanfeng Pan: Supervision, Investigation, Funding acquisition and Writing-Review.

\section{Animal Research (Ethics)}

No animal research was involved in the work reported.

\section{Consent to Participate (Ethics)}

All authors have approved the manuscript and agree with submission to Cellulose.

\section{Consent to Publish (Ethics)}

This work is original and has not been published elsewhere, nor is it under consideration by another journal.

\section{Introduction}

Controlled release of drug system has been extensively used to overcome the disadvantages of high drug concentration, high drug use and low drug utilization rate encountered in conventional drug formulations, enabling the steady release of drug at desirable concentrations (Ali and Ahmed 2018; Hou et al. 2018; Hou et al. 2019). The common drug carrier materials include film, microcapsules and hydrogel and so on. Among them, responsive hydrogels have attracted much attention because they not only protect drugs from adverse environment, but also control drug release by changing gel structure to respond to external environmental changes or stimuli (Pan et al. 2018; Wang et al. 2019a).

Hydrogels are polymeric materials with a three-dimensional (3D) network structure that can be prepared by physical crosslinking (e.g., hydrogen bonding, hydrophobic interactions, polyelectrolyte complexation, etc.) and chemical crosslinking (e.g., radiative crosslinking, disulfide bonds, imine bonds, etc.) of polymer chains (Ahmed 2015; Moharrami and Motamedi 2020; Sun et al. 2019; Thakur and Thakur 2015; Thinkohkaew et al. 2020; Wang et al. 2017; Wang et al. 2019b; Wei et al. 2014). It is able to absorb and retain large amounts of water (Iman et al. 2020; Islam et al. 2020). In recent years, hydrogels that can respond to stimuli from external conditions (e.g., temperature, redox, $\mathrm{pH}$, light, etc.) have attracted the attention of researchers (Chen et al. 2019; Dai et al. 2019; Nigmatullin et al. 2019; Shen et al. 2016; Wang et al. 2018). Cellulose and its derivatives can be used as suitable substrates for the preparation of responsive hydrogels due to their excellent biocompatibility and cost effectiveness.

Among various responsive hydrogels, cellulose-based hydrogels with $\mathrm{pH}$, temperature or redox responsiveness are often used in controlled release of drug systems (Kabir et 
al. 2018; Qiu and Hu 2013). Based on the enamine bonds and disulfide bonds, Liu et al. used wood pulp cellulose modified by tert-butyl acetoacetate (t-BAA) to combine it with cystamine dihydrochloride (CYS) to prepare a $\mathrm{pH} /$ redox double-responsive hydrogel, which can be loaded with rhodamine B to simulate drug release and has great application potential in drug sustained release (Liu et al. 2017). To enable the controlled release of agrochemicals, Hou et al. prepared a cellulose-based nanogel with $\mathrm{pH}$ and redox response using CYS etc. (Hou et al. 2019). Tetracycline hydrochloride (TH) is a broad-spectrum antibiotic, which is often used in hydrogels as a simulation drug (Chen et al. 2017; Liu et al. 2018a). Liu et al. made the cellulose nanofibers oxidized by 2,2,6,6-tetramethylpiperidine-1-oxyl to react with polydopamine to obtain $\mathrm{pH} /$ near-infrared dual-responsive hydrogel composite films and load TH for drug delivery (Liu et al. 2018b). Using chitosan microspheres and carboxymethyl cellulose (CMC), a redox responsive hydrogel film was prepared by Wang et al. (Wang et al. 2019a), which was loaded with TH and 5-fluorouracil for potential tumor therapy. In our previous work, we conducted relevant studies on the preparation of hydrogel based on sugarcane bagasse cellulose (SBC) and its application in controlled release of drug. On the one hand, $\mathrm{pH} /$ temperature responsive interpenetrating polymer network (IPN) hydrogels ware also prepared in our previous work using SBC, $\mathrm{CMC}$ and poly ( $\mathrm{N}$-isopropylacrylamide) as carriers, which was loaded with bovine serum albumin to simulate the controlled release of drug (Pan et al. 2018). Moreover, the oxidized SBC was reacted with methacrylic anhydride, cystamine bisacrylamide and $\mathrm{N}$-isopropylacrylamide to obtain temperature/redox responsive nanogels, and the sustained drug release of doxorubicin hydrochloride was achieved under different conditions (Pan et al. 2021).

To further improve the performance of cellulose-based hydrogels, particularly for those sugarcane bagasse-based ones which have not been fully explored yet, introducing the dynamic structure of enamine bonds and disulfide bonds onto cellulosic chains is essential for rendering the hydrogels redox/pH dual-responsive and meanwhile maintain their biocompatibility and biodegradability. Therefore, in this work, we modified the sugarcane bagasse cellulose first to enhance its reactivity. Specifically, sugarcane bagasse cellulose purified from sugarcane bagasse pulp was acetoacetylated to obtain bagasse cellulose acetoacetate (BCAA), followed by reaction with CYS to synthesize a redox/pH dual-responsive cellulose-based hydrogel (Scheme 1). In addition, the controlled release of tetracycline hydrochloride loaded in the hydrogel and its antibacterial activity against Staphylococcus aureus (S. aureus) and Escherichia coli (E. coli) were also studied. The resulting responsive hydrogel has a wide application prospect in controlled release of drug etc. 

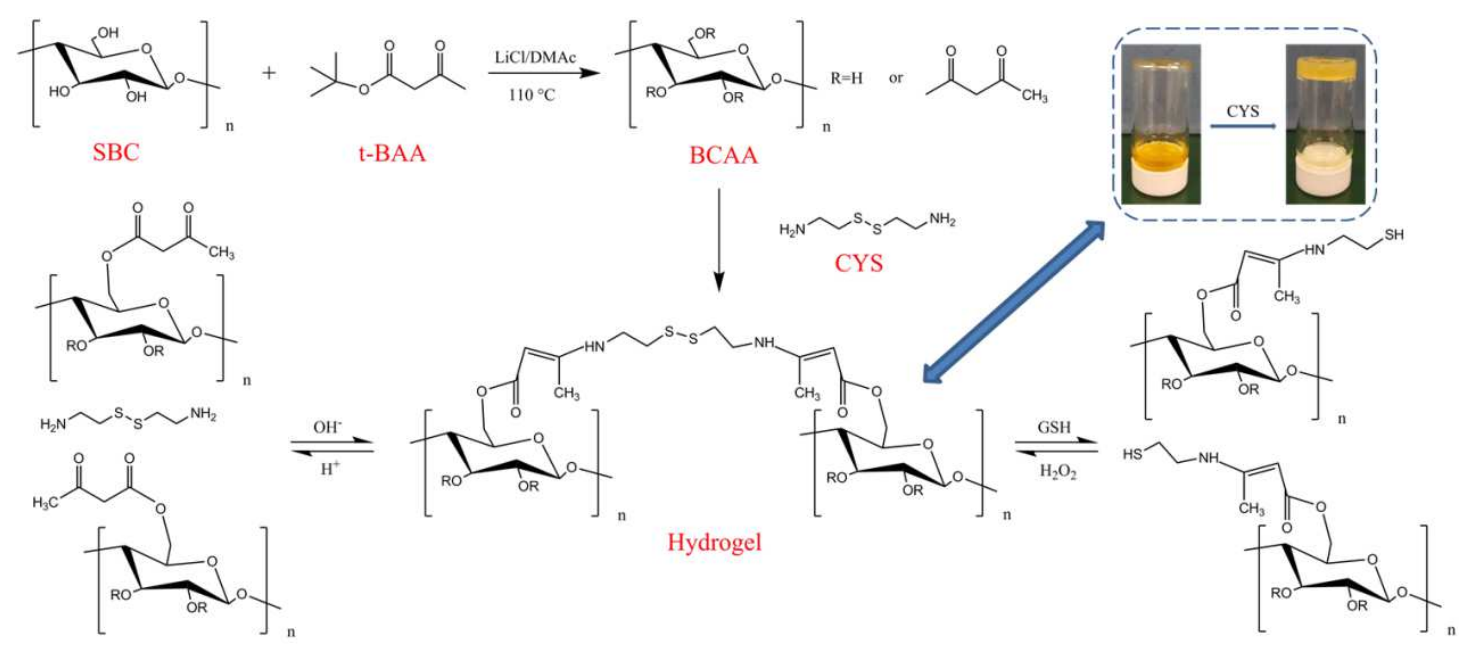

Scheme 1 Preparation of sugarcane bagasse cellulose-based hydrogel and its response to redox $/ \mathrm{pH}$

\section{Experimental}

\section{Materials}

The sugarcane bagasse pulp was obtained from Guangxi Sugar Industrial Corp, China. $\mathrm{N}$, N-dimethyl acetamide (DMAc), methanol and dimethyl sulfoxide (DMSO) were provided from Guangdong Guanghua Sci-Tech Co., Ltd. Anhydrous lithium chloride and tert-butyl acetoacetate were obtained from Shanghai Macklin Biochemical Co., Ltd. 4-dimethyl-pyridine (DMAP), cystamine dihydrochlorate, glutathione (GSH) and tetracycline hydrochloride were purchased from Shanghai Aladdin Biochemical Technology Co., Ltd. S. aureus (CMCC (B) 26003) and E. coli (ATCC 25922) were purchased from Shanghai Luwei Technology Co., Ltd. Candida albicans (C. albicans) (CMCC (F) 98001) was provided from Guangdong Huankai Microbial Sci. \& Tech. Co., Ltd. All chemicals were analytical grade, and used without further purification.

\section{Methods}

\section{The preparation of $B C A A$}

Sugarcane bagasse pulp was first pretreated with sodium chlorite and potassium hydroxide to obtain the sugarcane bagasse cellulose (SBC) (Pan et al. 2019). According to the Van Soest method (Pabon-Pereira et al. 2020; Van Soest 1963; Van Soest and Jones 1968), the contents of cellulose in sugarcane bagasse pulp and SBC were about $79 \%$ and $90 \%$, respectively. $2.0 \mathrm{~g}$ of SBC was dispersed in $40 \mathrm{~mL}$ of DMAc and placed in four flasks. Under the protection of nitrogen, it was activated at $150{ }^{\circ} \mathrm{C}$ for $30 \mathrm{~min}$, then cooled to $80^{\circ} \mathrm{C}$, and added $2.0 \mathrm{~g}$ anhydrous lithium chloride, stirring at constant temperature for $2 \mathrm{~h}$, then kept stirring overnight at room 
temperature to obtain light yellow transparent viscous cellulose ionic solution. Under the protection of nitrogen, DMAP $\left(15 \mathrm{mg} / \mathrm{g}\right.$ cellulose) was added at $110{ }^{\circ} \mathrm{C}$, followed by dropwise-adding $14.8 \mathrm{~g}$ of t-BAA. The reactant was stirred for $3 \mathrm{~h}$ and then cooled. The product BCAA was precipitated by methanol, washed by Soxhlet extraction, and then dried in a vacuum oven at $60^{\circ} \mathrm{C}$ for $24 \mathrm{~h}$.

\section{The preparation of hydrogel}

DMSO was used to dissolve BCAA to make BCAA solution. CYS was dissolved in sodium bicarbonate solution to obtain $5 \mathrm{wt} \%$ CYS aqueous solution. Generally, the CYS aqueous solution was mixed evenly at a mass ratio of 1:5 with the BCAA solution with different mass concentrations at room temperature, and the mixture was placed in $37{ }^{\circ} \mathrm{C}$ for gelation to obtain the BCAA/CYS hydrogel. According to the different mass concentrations ( $1 \mathrm{wt} \%, 1.5 \mathrm{wt} \%$, and $2 \mathrm{wt} \%$ ) of BCAA, the samples are denoted as BCAA1/CYS, BCAA1.5/CYS and BCAA2/CYS hydrogels. The hydrogel was immersed in deionized water for three days to remove unreacted solvents and solutes.

\section{Characterization}

The morphology of sugarcane bagasse cellulose, bagasse cellulose acetoacetate and hydrogel sample were observed using a scanning electron microscope (SEM, S-3400N, Hitachi, Japan). The hydrogel was frozen at ultra-low temperature and then freeze-dried. In order to analyze the internal structure of the hydrogel, the hydrogel was broken under liquid nitrogen, and the cross section of the hydrogel was coated with gold prior to SEM observation.

The samples or products were ground into powder and mixed with $\mathrm{KBr}$ for Fourier transform infrared scanning (FTIR, Frontier, PerkinElmer, USA) with scanning range of $400-4000 \mathrm{~cm}^{-1}$.

X-ray diffraction (XRD, Smartlab $3 \mathrm{KW}$, RigaKu, Japan) was used to reveal the crystal structures of bagasse cellulose $(\mathrm{BC}), \mathrm{SBC}$ and BCAA in the range of $2 \theta=$ $4-50^{\circ}$.

Hydrogen spectrum testing of BCAA samples using a ${ }^{1} \mathrm{H}$ nuclear magnetic resonance (NMR) spectrometer (NMR, Avance III HD500, Bruker, Germany), $3 \mathrm{mg}$ of BCAA was dissolved in $0.6 \mathrm{~mL}$ of DMSO-d6 at $60{ }^{\circ} \mathrm{C}$, and the sample was scanned 64 times. ${ }^{1} \mathrm{H}$ NMR was employed to characterize the resulting BCAA: ${ }^{1} \mathrm{H}$ NMR $(500 \mathrm{MHz}$, DMSO-d 6$), \delta(\mathrm{ppm})=3.5-6.0(\mathrm{AGU}), 3.62\left(-\mathrm{CH}_{2}-\right.$, acetoacetate), 2.05-2.45 $\left(-\mathrm{CH}_{3}\right.$, acetoacetate), 2.5 (DMSO), $3.33\left(\mathrm{H}_{2} \mathrm{O}\right)$. The degree of substitution (DS) of BCAA was calculated according to Equation (1), as shown below 


$$
\mathrm{DS}=\frac{I\left(\mathrm{CH}_{3}\right)_{A A} \times 7}{I_{A G U} \times 3}
$$

182

183

184

185

Where $I\left(\mathrm{CH}_{3}\right)_{A A}$ is the integration area of methyls on acetoacetate group, and $I_{A G U}$ is the integration value of hydrogen on anhydroglucose ring of BCAA.

Solubility of the bagasse cellulose derivative BCAA was tested in DMSO at $60{ }^{\circ} \mathrm{C}$ at a concentration of $1 \mathrm{wt} \%$.

\section{Stability of hydrogel in phosphate buffer saline (PBS) solution}

The hydrogel was prepared and a certain amount of PBS solution $(\mathrm{pH}=7.4)$ was added to observe the swelling state of the hydrogel immersed in different time $(24 \mathrm{~h}$, $48 \mathrm{~h}, 72 \mathrm{~h}$ ) at room temperature.

\section{Water retention tests}

Different lyophilized hydrogels were immersed in deionized water. After reaching the swelling equilibrium, the hydrogels were weighed after removing excess water on the surface to calculate the water retention rate of different hydrogels. The water retention rate was calculated according to Equation (2).

$$
\text { Water retention rate }(\%)=\frac{W_{1}-W_{2}}{W_{1}} \times 100
$$

Where $W_{1}$ is the weight of the wet hydrogel, and $W_{2}$ is the weight of the lyophilized hydrogel.

\section{Drug loading and release of hydrogel}

Different freeze-dried hydrogels were soaked in $10 \mathrm{~mL}$ of $1 \mathrm{mg} / \mathrm{mL} \mathrm{TH}$ aqueous solution and swollen for $24 \mathrm{~h}$ to obtain TH-loaded (TH/BCAA/CYS) hydrogels. Deionized water was used to remove the residual $\mathrm{TH}$ on the surface after the hydrogels completely swelled. The remaining $\mathrm{TH}$ was collected and volume-stabilized in a $250 \mathrm{~mL}$ volumetric bottle, and the drug loading rate (DLR) and the drug encapsulation efficiency (DEE) of the hydrogel was calculated. DLR and DEE were calculated according to Equation (3) and (4).

$$
\operatorname{DLR}(\%)=\frac{W_{\text {drug-loaded }}}{W_{\text {drug-loaded }}+W_{\text {dry-hydrogel }}} \times 100
$$


Where $W_{\text {drug-loaded }}$ is the amount of drug loaded into hydrogel, $W_{\text {dry-hydrogel }}$ is the quality of lyophilized hydrogel and $W_{\text {drug-added }}$ is the initial total amount of the drug.

The drug-loaded hydrogel was placed in a flask and $10 \mathrm{~mL}$ buffer solutions with different $\mathrm{pH}$ or GHS contents were added and put into a thermostatic water bath oscillator for drug release $\left(37^{\circ} \mathrm{C}, 100 \mathrm{rpm}\right)$. At the set time, $4 \mathrm{~mL}$ of drug released solution were removed and the same volume of buffer solution was added. The solution was analyzed by ultraviolet spectrophotometer. Equation (5) and (6) were used to calculate the cumulative release and release rate.

$$
\text { Cumulative release }(\%)=\frac{10 C_{n}+\sum C_{n-1} \times 4}{W_{\text {drug-loaded }}} \times 100
$$

$$
\text { Release rate }(\mathrm{mg} / \mathrm{h})=\frac{W_{\text {drug }}}{\left(t_{n}-t_{n-1}\right)}
$$

Where $C_{n}$ is the concentration of TH released when sampled at the $\mathrm{n}$ times and $W_{d r u g}$ is the amount of TH released during the time period from $t_{n-1}$ to $t_{n}$.

\section{Drug release kinetics}

To reveal the mechanism and kinetics of drug release from hydrogels, drug release data were fitted to various kinetic models, which are the zero order model (Eq. (7)), the first order model (Eq. (8)), the Higuchi model (Eq. (9)), and the Korsmeyer-Peppas model (Eq. (10)), respectively (Liu et al. 2018a; Pandey et al. 2016).

$$
\begin{gathered}
\frac{M_{t}}{M_{\infty}}=K_{0} t \\
\ln \left(1-\frac{M_{t}}{M_{\infty}}\right)=-K_{1} t
\end{gathered}
$$

$$
\frac{M_{t}}{M_{\infty}}=K_{2} t^{\frac{1}{2}}
$$

$$
\frac{M_{t}}{M_{\infty}}=K_{3} t^{n}
$$

Where $M_{t}$ and $M_{\infty}$ are the cumulative amount of drug released at time $t$ and infinite time, respectively; $K_{0}, K_{1}, K_{2}$, and $K_{3}$ represent the release rate constants of corresponding models, respectively; $n$ is the release exponent. 
The inhibition zone method was used to study the antibacterial activity of pure (BCAA1/CYS) hydrogel and drug-loaded hydrogel (TH/BCAA1/CYS) against E. coli, $S$. aureus and $C$. albicans. The BCAA1/CYS hydrogels and TH/BCAA1/CYS hydrogels were prepared according to the previous preparation method. Freeze-dried samples were pressed into uniform size wafers with a tablet press, and wafers were placed in ultraviolet light to sterilize for $60 \mathrm{~min}$. The bacterial suspension was diluted to $10^{6} \mathrm{CFU} / \mathrm{mL}$ by sterile PBS solution. The wafers was placed on the agar plate coated with $0.2 \mathrm{~mL}$ of $10^{6} \mathrm{CFU} / \mathrm{mL}$ bacterial suspension by aseptic tweezers, and was incubated at $37^{\circ} \mathrm{C}$ for $24 \mathrm{~h}$. The antibacterial activity of the samples was evaluated by observing the size of inhibition zone which was presented in $\mathrm{mm}$.

The antibacterial activities of different hydrogel samples against $S$. aureus and E. coli were evaluated in terms of growth inhibition rates, and the antibacterial activities of TH/BCAA1/CYS hydrogel under different $\mathrm{pH}$ and redox conditions within $4 \mathrm{~h}$ were determined. The mixture of $10 \mathrm{~mL}$ of bacterial suspension $\left(10^{6} \mathrm{CFU} / \mathrm{mL}\right)$ and $0.02 \mathrm{~g}$ sample was shaken at $100 \mathrm{rpm}$ at $37^{\circ} \mathrm{C}$ for $24 \mathrm{~h}$ or $4 \mathrm{~h}$ in a thermostatic water bath oscillator. Then, $1 \mathrm{~mL}$ of bacterial suspension that has been acted on by the sample was added to $9 \mathrm{~mL}$ of sterile PBS solution and diluted $10^{4}$ times. $0.1 \mathrm{~mL}$ of diluted bacterial suspension was applied to agar plate and cultured at $37{ }^{\circ} \mathrm{C}$ for $24 \mathrm{~h}$. The number of colonies on agar plate was calculated, the growth inhibition rate was obtained, and repeated three times. In addition, the bacterial suspension was diluted under different $\mathrm{pH}$ and redox conditions with the corresponding buffer solution. According to Equation (11), the growth inhibition rate of hydrogel samples was calculated.
Where $A$ is the colony number from the control, $B$ is the colony number of drug-loaded hydrogel.

\section{Results and discussion}

\section{Preparation and characterization of BCAA and hydrogel}

The samples were further characterized by FTIR (Fig. 1a). Compared with SBC, the characteristic peaks of dicarbonyl bonds in acetoacetyl groups appeared in the spectra of BCAA at 1710 and $1750 \mathrm{~cm}^{-1}$, and also appeared in the infrared spectrum of the hydrogel. The characteristic peak at $2596 \mathrm{~cm}^{-1}$ was attributed to the stretching vibration the disulfide bonds. In addition, there are new absorption peaks at 1652 and $1605 \mathrm{~cm}^{-1}$ in the spectrum of the resulting hydrogel, which are the vibration 
absorption peaks of enamine bonds formed by the reaction between amino groups and acetoacetyl groups. After the cellulose hydrogel was loaded with drugs, it was also subjected to FTIR analysis (Fig. 1b). $1579 \mathrm{~cm}^{-1}$ and $1614 \mathrm{~cm}^{-1}$ are the characteristic absorption peaks corresponding to the carbonyl group on ring a and ring $\mathrm{c}$ of TH. Comparing the infrared spectra before and after the drug loading, it was found that two corresponding characteristic peaks were slightly shifted, implying the loading of drug into the hydrogel.

SEM images of SBC, BCAA and Hydrogel are shown in Fig. 1c, d and e, in which SBC was a long strip with relatively flat surface and a few grooves and cracks. The morphology of cellulose after acetoacetylation had obvious changes compared with SBC. The surface of BCAA particles was rough, honeycomb-shaped, and filled with voids. It can be seen that after the pretreatment of cellulose reacts with t-BAA to undergo transesterification, the attached hydroxyl groups are converted into acetoacetyl groups, resulting in a relatively flat structure on the surface becoming rough and full of voids inside. The cross-section of the hydrogel formed after the cross-linking reaction of BCAA and CYS presents a porous structure, that is, a three-dimensional network structure.
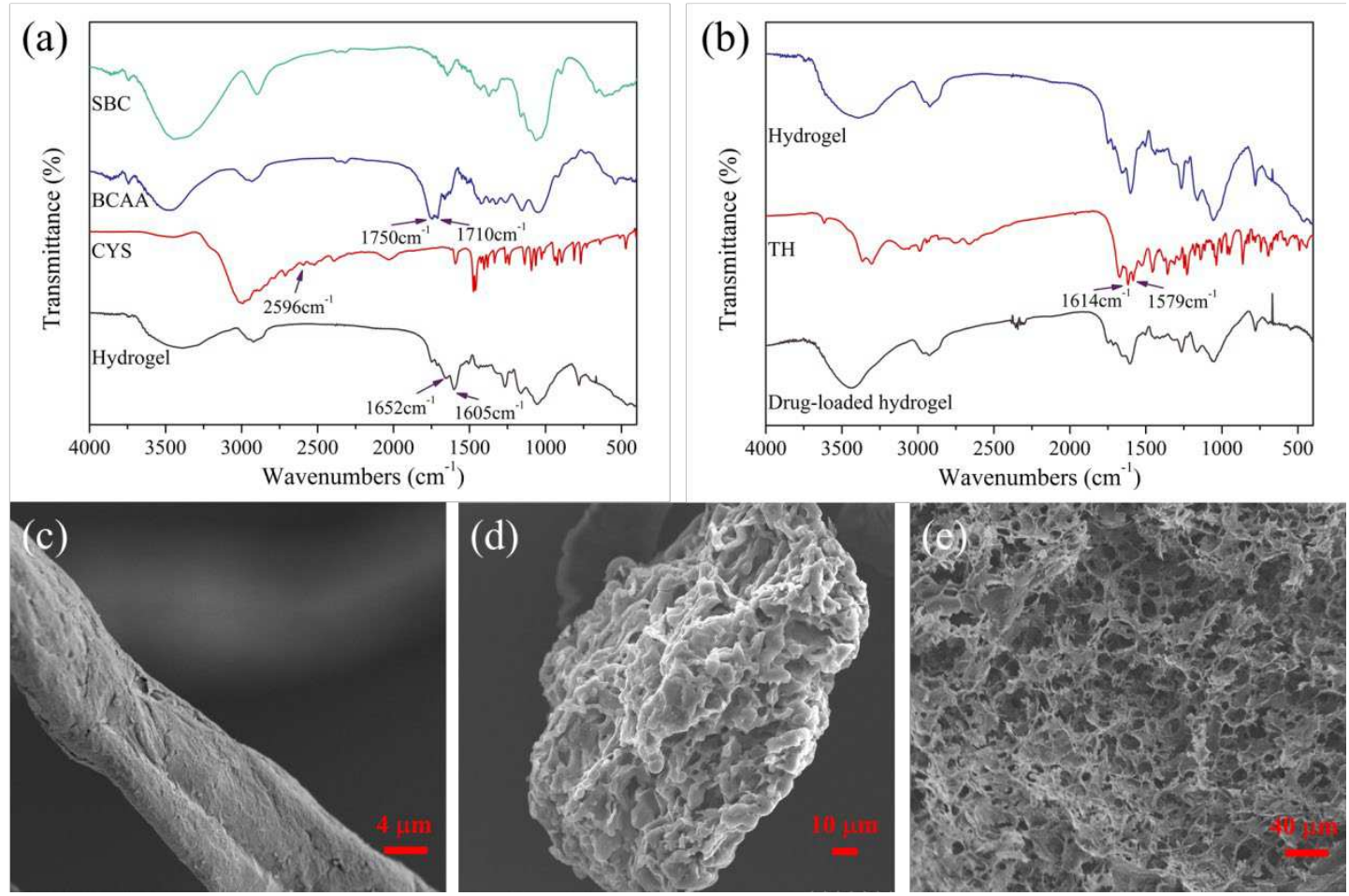

Fig. 1 (a) FTIR spectra of SBC, BCAA, CYS and Hydrogel, (b) FTIR spectra of Hydrogel, TH and Drug-loaded hydrogel, SEM images of SBC (c), BCAA (d) and hydrogel (e) 
The crystal structures of $\mathrm{BC}, \mathrm{SBC}$ and $\mathrm{BCAA}$ were analyzed by $\mathrm{XRD}$; whereas, the DS of BCAA was quantified based on the results obtained from ${ }^{1} \mathrm{H}$ NMR (Fig. 2). As can be seen from the XRD spectrum of $\mathrm{BC}$, the characteristic peaks appeared at $16.2^{\circ}$, $22.6^{\circ}$, and $34.8^{\circ}$, representing typical cellulose I crystal structure. After pretreatment of SBC, peak intensity became stronger at $2 \theta=22.6^{\circ}$; while $2 \theta=20.3^{\circ}$ appeared belongs to the characteristic peak of cellulose II crystal structure, demonstrating the effect of alkali treatment on cellulose crystal structure. Moreover, the crystal structure of BCAA was completely transformed into cellulose II crystal structure (Fig. 2a), and the crystallinities of SBC and BCAA were $80.8 \%$ and $11.5 \%$, respectively. This indicated that under homogeneous condition, the hydroxyl groups of cellulose glucose units were transesterified by t-BAA, thus changing the crystal structure of cellulose.

The ${ }^{1} \mathrm{H}$ NMR spectra of BCAA are shown in Fig. 2b. The chemical shifts at $\delta=$ 2.05-2.45 ppm were attributed to the characteristic peak of the methyl groups in the acetoacetyl group (Edgar 1995), and the chemical shifts at $\delta=3.62 \mathrm{ppm}$ were the chemical shift of the methylene groups. The range of $\delta=3.5-6.0 \mathrm{ppm}$ belong to the chemical shifts of hydrogen on the glucose ring in cellulose. The DS can be controlled by varying molar ratio of cellulose glucose ring to t-BAA or catalyst. The results of the DS of BCAA prepared under different conditions and the solubility in DMSO are shown in Table 1. The DS increased from 0.77 to 1.70 with increasing the molar ratio of anhydroglucose of cellulose to t-BAA from 1:3 to 1:8 in the presence of DMAP as catalyst. Furthermore, by fixing the molar ratio of 1:8, the DS of BCAA increased from 1.25 to 1.70 with the addition of DMAP. In additional, the sample 4 can be completely dissolved in DMSO.

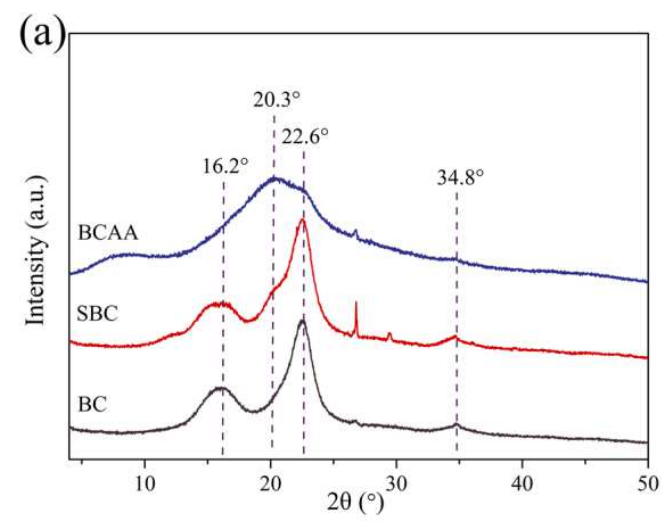

(b)
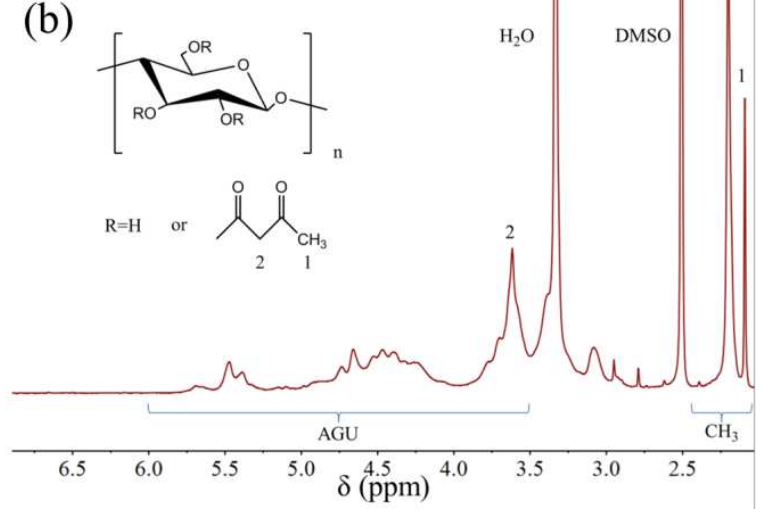

Fig. 2 (a) XRD of BC, SBC and BCAA, (b) ${ }^{1} \mathrm{H}$ NMR of BCAA 
Table 1 Different reaction conditions of cellulose acetoacetate and its solubility in DMSO

\begin{tabular}{ccccc}
\hline Sample & Molar ratio $^{\mathrm{a}}$ & Catalyst & DS & Solubility $^{\mathrm{b}}$ (DMSO) \\
\hline 1 & $1: 3$ & DMAP & 0.77 & + \\
2 & $1: 4$ & DMAP & 1.01 & + \\
3 & $1: 6$ & DMAP & 1.48 & ++ \\
4 & $1: 8$ & DMAP & 1.70 & + \\
5 & $1: 8$ & & 1.25 & +
\end{tabular}

${ }^{\mathrm{a}}$ Molar ratio of cellulose glucose ring and t-BAA, ${ }^{\mathrm{b}}$ completely soluble $(++)$, partially 321 soluble $(+)$

\section{The stability and water retention of hydrogel}

323 In order to verify the stability of cellulose hydrogel under physiological conditions $324\left(25^{\circ} \mathrm{C}, \mathrm{pH}=7.4\right)$. After preparing the hydrogel in the bottle, mark its initial surface and soak it in the buffer solution for different time. The swelling performance was recorded by observation and digital photography. As shown in Fig. 3a, the hydrogel remained in its initial state after $72 \mathrm{~h}$ of soaking without significant swelling, indicating that the hydrogel has good stability under physiological conditions.

329 Water retention can be used to measure the reswelling performance of hydrogels after 330 freeze-drying. Fig. 3b shows the water retention properties of different hydrogels in 331 deionized water. As the concentration of BCAA was increased, the water retention of the hydrogel was decreased due to the increasing of the internal crosslinking of the hydrogel induced by BCAA. The highly cross-linked hydrogels are more compact and stable, thus enhancing the stability and reducing the reswelling of hydrogel after freeze-drying. 
(a)

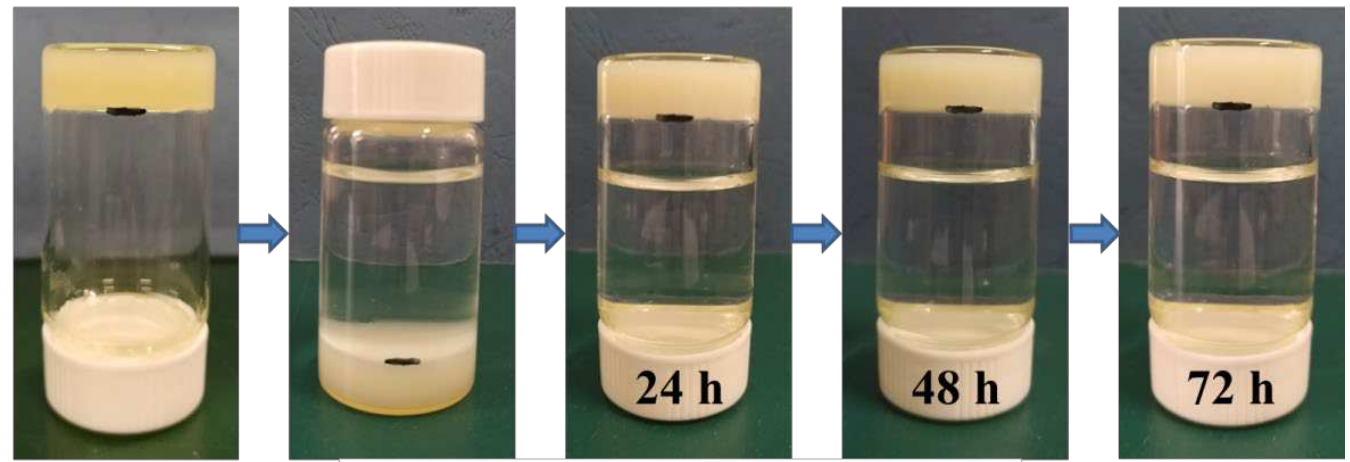

(b)

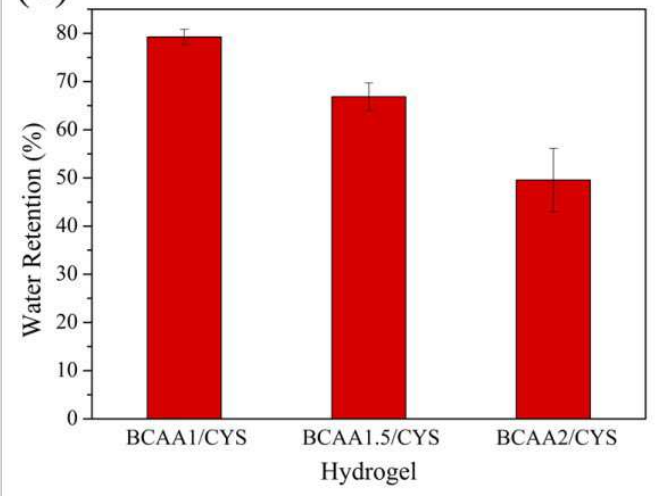

337 Fig. 3 (a) Stability of cellulose hydrogel in PBS solution (24 h, 48 h, 72 h), (b) water retention of different hydrogels

\section{The drug loading and release}

Hydrogels can be used as drug carriers in the field of biomedicine. The antibiotics (tetracycline hydrochloride) was used a model drug and loaded in different hydrogels. The drug release behaviors of hydrogel under different $\mathrm{pH}$ or redox conditions were investigated. The results are shown in Fig. 4.

The UV-visible spectrophotometer was used to monitor the concentration of TH in different buffer solution systems based on the standard calibration curves (Fig. 4a) obtained at the maximum absorption wavelength $(\lambda=360 \mathrm{~nm})$. When TH was loaded on different hydrogels, the drug loading rate and drug encapsulation efficiency decreased with the increase of BCAA concentration (Fig. 4b). The reason may be that hydrogels mainly load drugs through physical adsorption. At the same time, with the increase of cross-linking degree, the water retention rate of hydrogels decreases, leading to the decrease of the load performance of hydrogels due to relatively weak water absorption. The drug encapsulation efficiency and drug loading rate of TH/BCAA1/CYS hydrogel were $37.8 \%$ and $7.1 \%$, respectively.

Fig. 4c shows the drug release performance of TH/BCAA1/CYS hydrogel under different release conditions $(\mathrm{pH}=7.4, \mathrm{pH}=5.0, \mathrm{pH}=7.4$ with $10 \mathrm{mM} \mathrm{GSH}$, and $\mathrm{pH}$ $=5.0$ with $10 \mathrm{mM} \mathrm{GSH}$, respectively). At $\mathrm{pH}=7.4$, there was no obvious burst 
release of cellulose hydrogel, and the total drug release within $24 \mathrm{~h}$ was about $63 \%$. The hydrogel exhibited an excellent sustained release property, clearly demonstrating the good feasibility of loading drug into hydrogel network scaffolds for sustained release. When $\mathrm{pH}$ was adjusted to 5.0, the total drug release of cellulose hydrogel increased, and reached the maximum sustained release within the first $7 \mathrm{~h}$. After the addition of $10 \mathrm{mM} \mathrm{GSH}$, the drug release rate of cellulose hydrogel was significantly accelerated (Fig. 4d), and $75 \%$ of the total drug load was released within $6.5 \mathrm{~h}$. And when the $\mathrm{pH}$ value was reduced and GSH was introduced at the same time, the release rate and the total amount of drug release were greatly increased. The results showed that the hydrogel obtained by the reaction of BCAA and CYS allowed the drug to be released slowly under physiological environmental conditions. Meanwhile, the existence of disulfide bonds and enamine bonds in the hydrogels, under redox and weakly acidic conditions, the three-dimensional network structure constructed by cross-linking of covalent bonds will be broken, thus accelerating the release of loaded drugs. In other words, the results clearly demonstrated that the as-prepared hydrogel has dual responsiveness of redox and $\mathrm{pH}$, permitting the controlled release of drug.

(a)

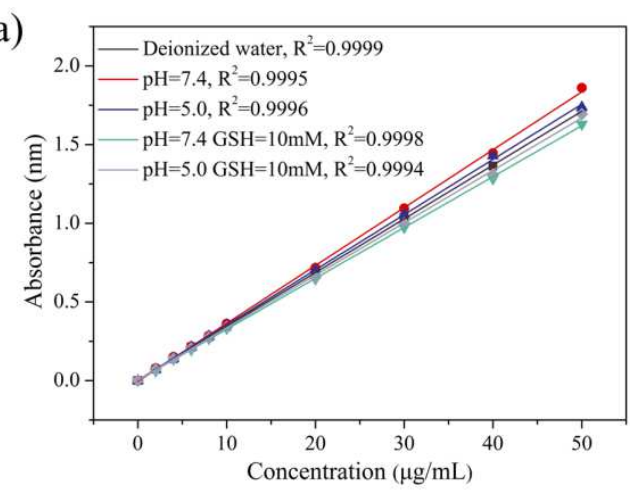

(c)

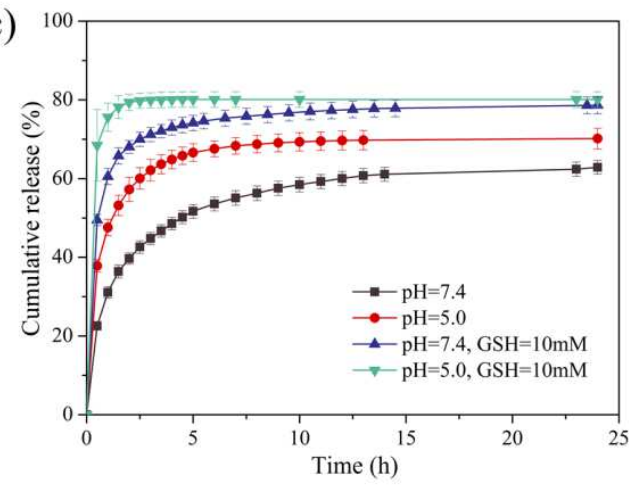

(b)

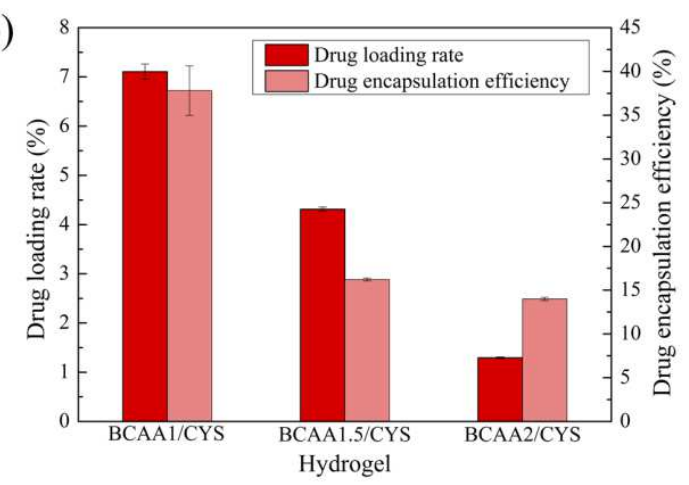

(d)

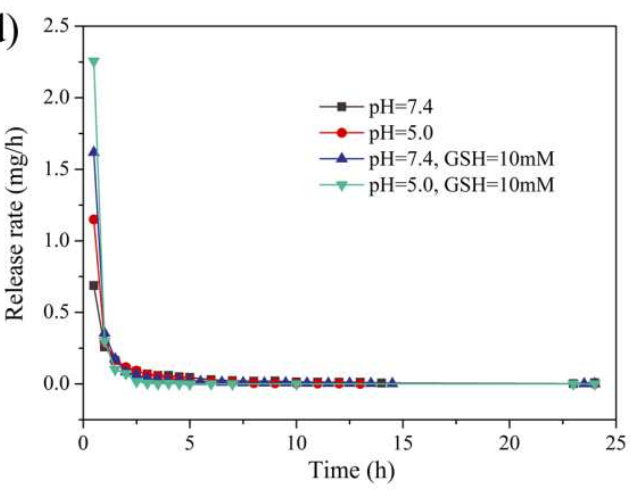

Fig. 4 (a) Standard curve of TH in different slow-release environments, (b) the drug loading rate and encapsulation efficiency of different hydrogels for $\mathrm{TH}$, (c) the cumulative release of drug-loaded hydrogels under different conditions $(\mathrm{pH}=7.4, \mathrm{pH}$ $=5.0, \mathrm{pH}=7.4$ with $10 \mathrm{mM} \mathrm{GSH}$, and $\mathrm{pH}=5.0$ with $10 \mathrm{mM} \mathrm{GSH}$, respectively), (d) the release rates versus time at different conditions $(\mathrm{pH}=7.4, \mathrm{pH}=5.0, \mathrm{pH}=7.4$ with $10 \mathrm{mM} \mathrm{GSH}$, and $\mathrm{pH}=5.0$ with $10 \mathrm{mM} \mathrm{GSH}$, respectively) 


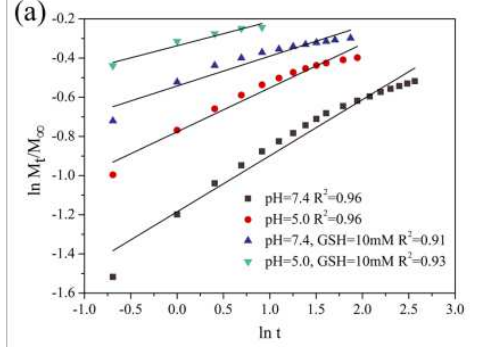
Fickian diffusion. (b)

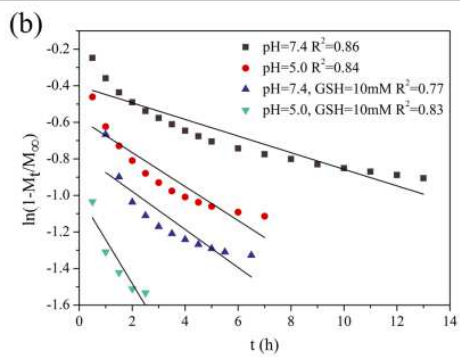

(c)

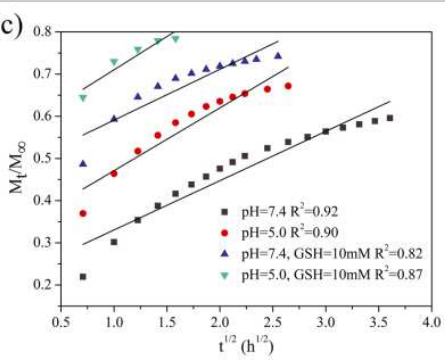

391

392

393

394

395

396

397

398

In order to understand the drug release kinetics of BCAA/CYS hydrogel in different conditions, the release data were analyzed based on the zero order, first order, Higuchi, and Korsmeyer-Peppas models (Fig. 5 and 6). According to the fitting results of drug release data of BCAA/CYS hydrogel in different conditions (Table 2), the correlation coefficient $\mathrm{R}^{2}$ of the Korsmeyer-Peppas model was higher than those from other models, which indicated that the drug release kinetics of BCAA/CYS hydrogel follows the Korsmemeyer-Peppas model well. In addition, the exponent (n) in Table 2 suggested that the release mechanism of BCAA/CYS hydrogel is mainly driven by

Fig. 5 (a) Plot of $\ln \left(\mathrm{M}_{t} / \mathrm{M}_{\infty}\right)$ versus $\operatorname{lnt}$ for the release of $\mathrm{TH}$ from BCAA/CYS hydrogel in different release conditions $(\mathrm{pH}=7.4, \mathrm{pH}=5.0, \mathrm{pH}=7.4$ with $10 \mathrm{mM}$ $\mathrm{GSH}$, and $\mathrm{pH}=5.0$ with $10 \mathrm{mM} \mathrm{GSH}$, respectively), (b) plot of $\ln \left(1-\mathrm{M}_{\mathrm{t}} / \mathrm{M}_{\infty}\right)$ versus $\mathrm{t}$ for the release of $\mathrm{TH}$ from $\mathrm{BCAA} / \mathrm{CYS}$ hydrogel in different release conditions $\mathrm{pH}=$ $7.4, \mathrm{pH}=5.0, \mathrm{pH}=7.4$ with $10 \mathrm{mM} \mathrm{GSH}$, and $\mathrm{pH}=5.0$ with $10 \mathrm{mM} \mathrm{GSH}$, respectively), (c) plot of $\mathrm{M}_{t} / \mathrm{M}_{\infty}$ versus $\mathrm{t}^{1 / 2}$ for the release of TH from BCAA/CYS hydrogel in different release conditions $(\mathrm{pH}=7.4, \mathrm{pH}=5.0, \mathrm{pH}=7.4$ with $10 \mathrm{mM}$ $\mathrm{GSH}$, and $\mathrm{pH}=5.0$ with $10 \mathrm{mM} \mathrm{GSH}$, respectively) 

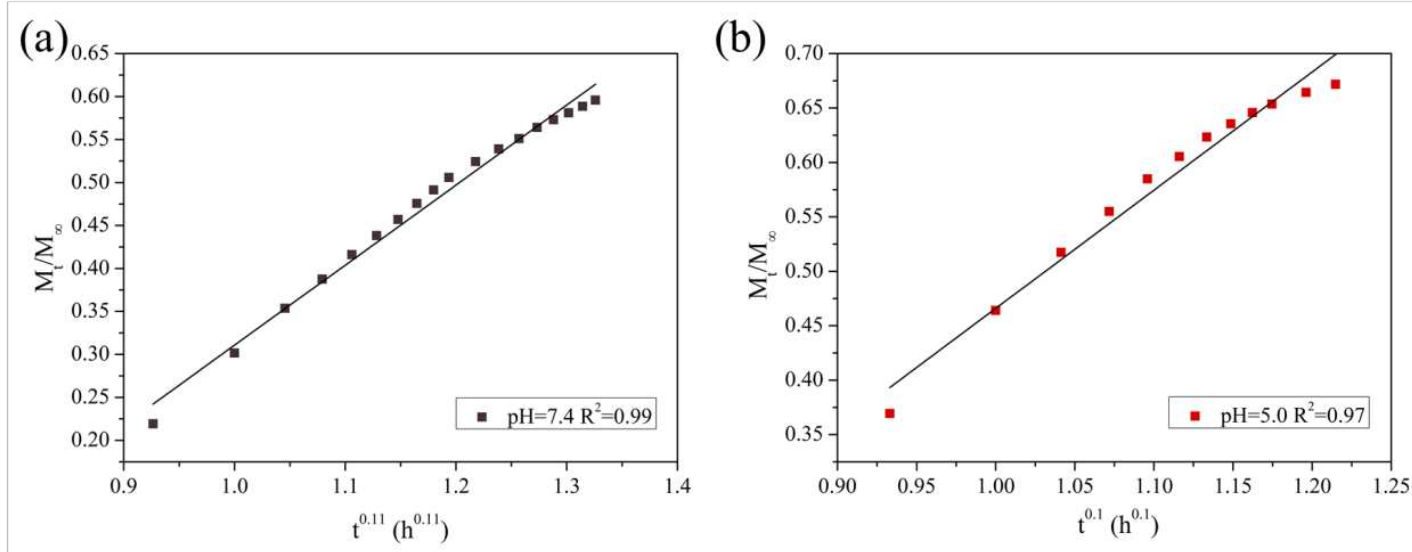

(c)
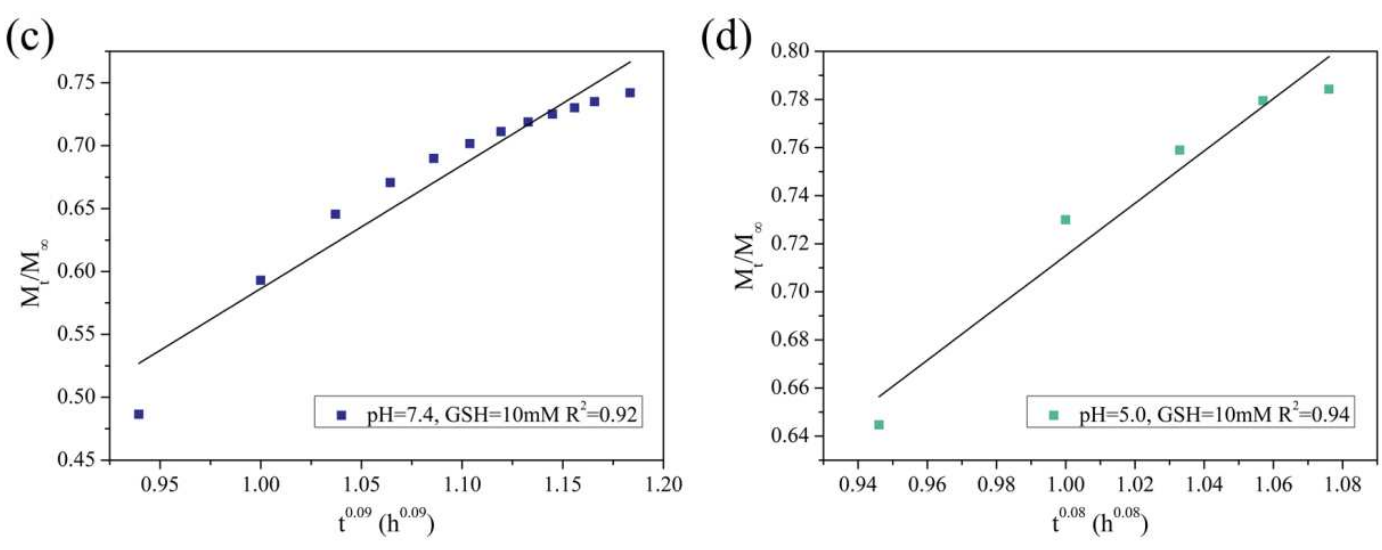

400

401

402

403

404

405

Fig. 6 Plot of $\mathrm{M}_{\mathrm{t}} / \mathrm{M}_{\infty}$ versus $\mathrm{t}^{\mathrm{n}}$ for the release of TH from BCAA/CYS hydrogel $(\mathbf{a}, \mathbf{b}$, $\mathbf{c}$, and $\mathbf{d}, \mathrm{n}=0.11,0.1,0.09,0.08$, respectively) in different release conditions ( $\mathrm{pH}=$ 7.4, $\mathrm{pH}=5.0, \mathrm{pH}=7.4$ with $10 \mathrm{mM} \mathrm{GSH}$, and $\mathrm{pH}=5.0$ with $10 \mathrm{mM} \mathrm{GSH}$, respectively)

Table 2 Release parameter for BCAA/CYS hydrogels in different release condition obtained by fitting in drug release data to different models for drug release kinetics

\begin{tabular}{|c|c|c|c|c|c|c|c|c|c|}
\hline \multirow[t]{2}{*}{ Sample $^{\mathrm{a}}$} & \multicolumn{2}{|c|}{ Zero order } & \multicolumn{2}{|c|}{ First order } & \multicolumn{2}{|c|}{ Higuchi model } & \multicolumn{3}{|c|}{ Korsmeyer-Peppas model } \\
\hline & $\mathrm{R}^{2}$ & $\mathrm{~K}$ & $\mathrm{R}^{2}$ & $\mathrm{~K}$ & $\mathrm{R}^{2}$ & $\mathrm{~K}$ & $\mathrm{R}^{2}$ & $\mathrm{~K}$ & $\mathrm{n}$ \\
\hline 1 & 0.96 & 0.29 & 0.86 & 0.05 & 0.92 & 0.12 & 0.99 & 0.93 & 0.11 \\
\hline 2 & 0.96 & 0.22 & 0.84 & 0.09 & 0.90 & 0.15 & 0.97 & 1.09 & 0.1 \\
\hline 3 & 0.91 & 0.15 & 0.77 & 0.10 & 0.82 & 0.12 & 0.92 & 0.98 & 0.09 \\
\hline 4 & 0.93 & 0.12 & 0.83 & 0.24 & 0.87 & 0.16 & 0.94 & 1.09 & 0.08 \\
\hline
\end{tabular}
condition for drug release $(\mathrm{pH}=7.4, \mathrm{pH}=5.0, \mathrm{pH}=7.4$ with $10 \mathrm{mM} \mathrm{GSH}$, and $\mathrm{pH}=$ 
409

410

411

412

413

414

415

416

417

418

419

420

421

422

423

424

425

426

427

428

429

430

431

432

433

434

435

436

437

438

439

440

441

442

443

\section{Antibacterial test}

TH is often used against bacterial infections caused by Gram-negative and Gram-positive bacteria, mainly by inhibiting the formation of bacterial proteins to achieve antibacterial effects. Based on the drug release experiment of hydrogel, we further studied the antibacterial properties of hydrogel loaded with drug against $S$. aureus, E. coli and C. albicans. The results from Fig. 7 showed that the BCAA1/CYS hydrogel had no inhibition zone formed in these three strains or no inhibitory effect on them. However, the TH/BCAA1/CYS hydrogel produced a zone of inhibition around $S$. aureus and E. coli with the size of the zone of inhibition at $36 \mathrm{~mm}$ and 34 $\mathrm{mm}$, respectively, indicating a reasonably good antibacterial effect on these two bacteria. The antibacterial effect is mainly derived from TH in the hydrogel, which was not covalently bonded, but loaded by physical adsorption. TH can be leached out from the hydrogel carrier and create antibacterial effect to some extent. However, the TH/BCAA1/CYS hydrogel was not effective against $C$. albicans.

We further studied the antibacterial properties of different drug-loaded dual-responsive hydrogels against $S$. aureus and E. coli (Fig. 8a). It can be seen from the data that the TH/BCAA1/CYS hydrogel with the largest load had a growth inhibition rate of over $98 \%$ against $S$. aureus and $E$. coli within $24 \mathrm{~h}$. Comparing the antibacterial test on $E$. coli, hydrogels with different drug loadings had slightly better antibacterial effects against $S$. aureus. In addition, the growth inhibition rate of TH/BCAA2/CYS hydrogel to $E$. coli is less than $50 \%$. Fig. $8 \mathrm{~b}$ shows the antibacterial activity of TH/BCAA/CYS hydrogels against $S$. aureus and $E$. coli under different $\mathrm{pH}$ and redox conditions. It is worth noting that the growth inhibition rates against $S$. aureus and E. coli of TH/BCAA1/CYS hydrogel were only $36.3 \%$ and $15.9 \%$ under $\mathrm{pH}=7.4$ within $4 \mathrm{~h}$, respectively. This suggested that TH/BCAA1/CYS hydrogel exhibited certain antibacterial activities to $S$. aureus and E. coli under physiological conditions, but that the antibacterial activities were not sufficiently high. However, when $\mathrm{pH}$ was reduced or GSH was added, the growth inhibition rates increased. After lowering the $\mathrm{pH}$ and adding GSH at the same time, the TH/BCAA1/CYS hydrogel exhibited the significantly improved antibacterial effects on $S$. aureus and E. coli, and the growth antibacterial rates reached $98.1 \%$ and $97.8 \%$, respectively. This is attributed to the breaking of enamine bonds and disulfide bonds in the hydrogel, triggered by dual-responsiveness, and the increasing of the release of TH. The excellent antibacterial activities indicated that BCAA/CYS hydrogels are promising used as smart or responsive drug carriers in the fields of biomedicine or aquaculture. 


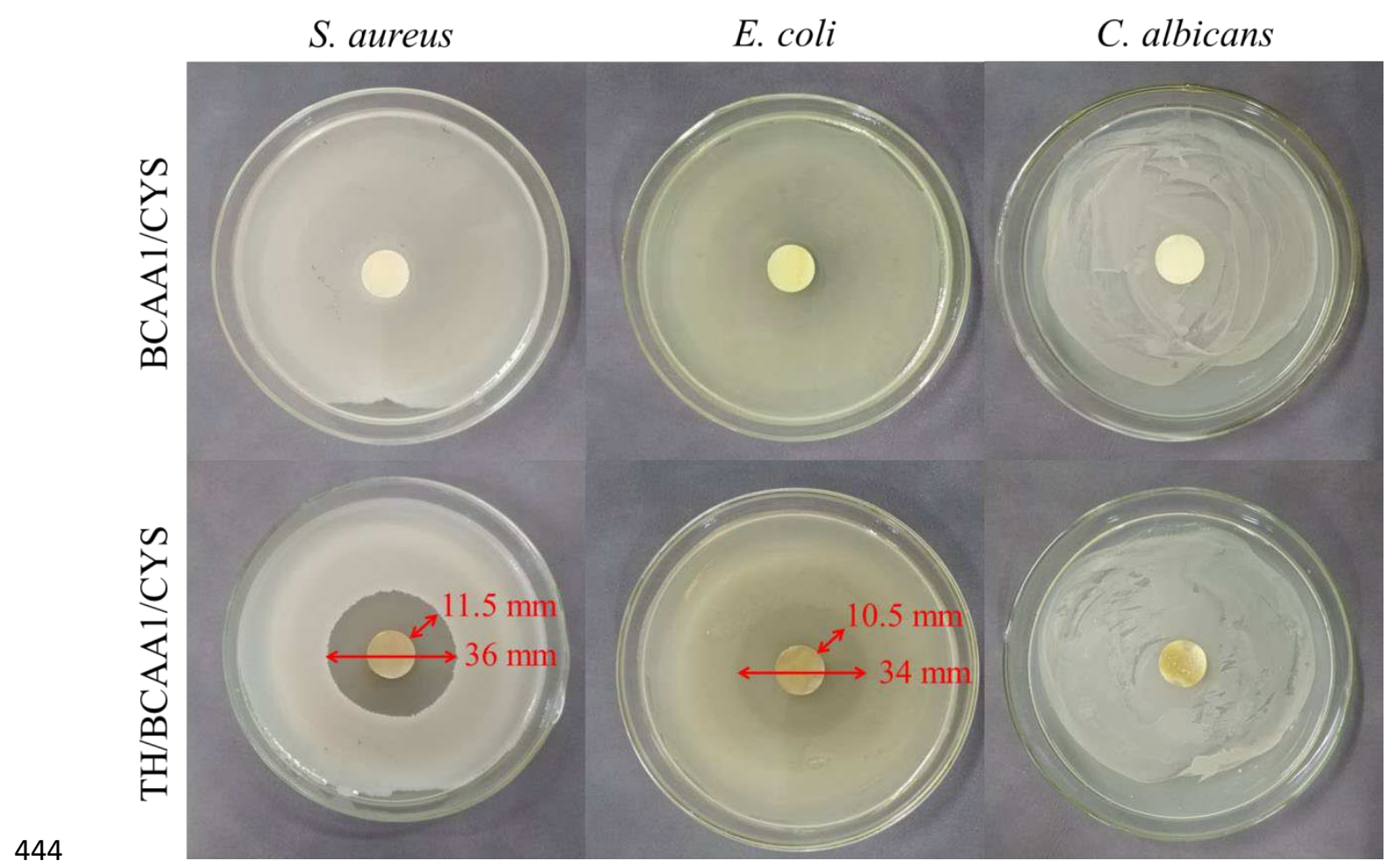

445 Fig. 7 The inhibition zone test of hydrogels (BCAA1/CYS and TH/BCAA1/CYS) against $S$. aureus, E. coli and C. albicans
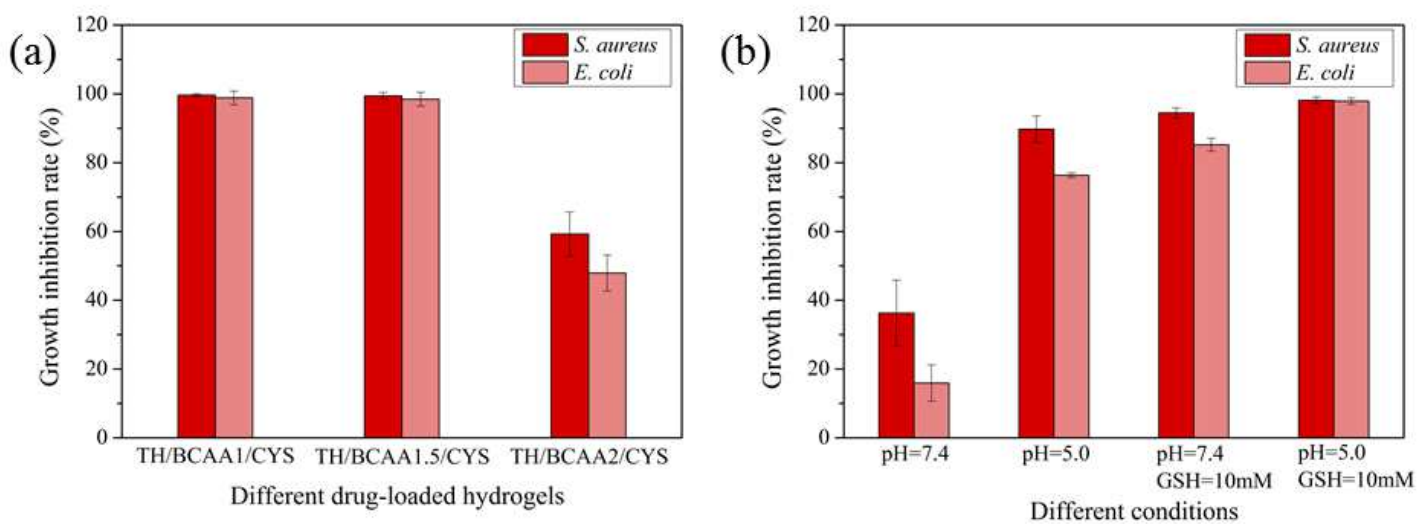

Fig. 8 (a) The growth inhibition rate of different drug-loaded hydrogels against $S$. aureus and E. coli, (b) the growth inhibition rate of TH/BCAA1/CYS hydrogel against $S$. aureus and $E$. coli within $4 \mathrm{~h}$ under different conditions $(\mathrm{pH}=7.4, \mathrm{pH}=5.0$, $\mathrm{pH}=7.4$ with $10 \mathrm{mM} \mathrm{GSH}$, and $\mathrm{pH}=5.0$ with $10 \mathrm{mM} \mathrm{GSH}$, respectively)

\section{Conclusions}

The cellulose or green-based hydrogel with redox/pH dual responsiveness was 
454

455

456

457

458

459

460

461

462

463

464

465

466

467

468

469

470

471

472

473

474

475

476

477

478

479

480

481

482

483

484

successfully prepared via introducing dynamic chemical bonds for the cross-linking between BCAA and CYS. The TH-loaded hydrogel allows the slow release of drug under neutral conditions due to the presence of enamine bonds and disulfide bonds, whereas the drug-loaded hydrogel can accelerate the release corresponding to the redox and weak acidity of environment. The release of BCAA/CYS hydrogel is mainly driven by Fickian diffusion and better described by Korsmeyer-Peppas model from a mechanistic point of view. In addition, this type of drug-loaded hydrogel demonstrated strong antibacterial activity against $S$. aureus and E. coli. Therefore, the redox and $\mathrm{pH}$ dual-responsive hydrogel developed in this work has great application prospects in biomedicine such as the controlled release of drugs and wound excipients.

\section{Acknowledgments}

This work was supported by the National Natural Science Foundation of China [grant number 22068006 \& 21306027] and the Dean Project of Guangxi Key Laboratory of Petrochemical Resource Processing and Process Intensification Technology [grant number 2019Z003].

\section{References}

Ahmed EM (2015) Hydrogel: Preparation, characterization, and applications: A review. J Adv Res 6:105-121. https://doi.org/10.1016/j.jare.2013.07.006

Ali A, Ahmed S (2018) A review on chitosan and its nanocomposites in drug delivery. Int J Biol Macromol 109:273-286. https://doi.org/10.1016/j.ijbiomac.2017.12.078

Chen H, Xing X, Tan H et al (2017) Covalently antibacterial alginate-chitosan hydrogel dressing integrated gelatin microspheres containing tetracycline hydrochloride for wound healing. Mater Sci Eng C 70:287-295. https://doi.org/10.1016/j.msec.2016.08.086

Chen N, Wang H, Ling C, Vermerris W, Wang B, Tong Z (2019) Cellulose-based injectable hydrogel composite for pH-responsive and controllable drug delivery. Carbohydr Polym 225. https://doi.org/10.1016/j.carbpol.2019.115207

Dai H, Zhang H, Ma L et al (2019) Green pH/magnetic sensitive hydrogels based on pineapple peel cellulose and polyvinyl alcohol: synthesis, characterization and naringin prolonged release. Carbohydr Polym 209:51-61. https://doi.org/10.1016/j.carbpol.2019.01.014

Edgar KJ, Arnold KM, Blount WW, Lawniczak JE, Lowman DW (1995) Synthesis and Properties of Cellulose Acetoacetates. Macromolecules 28:4122-4128. https://doi.org/10.1021/ma00116a011 
dual-functional redox-responsive hydrogel for soil remediation. Chem Commun 54:13714-13717. https://doi.org/10.1039/c8cc07872f

Hou X, Pan Y, Xiao H, Liu J (2019) Controlled Release of Agrochemicals Using pH and Redox Dual-Responsive Cellulose Nanogels. J Agric Food Chem 67:6700-6707. https://doi.org/10.1021/acs.jafc.9b00536

Iman M, Barati A, Safari S (2020) Characterization, in vitro antibacterial activity, and toxicity for rat of tetracycline in a nanocomposite hydrogel based on PEG and cellulose. Cellulose 27:347-356. https://doi.org/10.1007/s10570-019-02783-5

Islam MS, Alam MN, van de Ven TGM (2020) Sustainable cellulose-based hydrogel for dewatering of orange juice. Cellulose 27:7637-7648. https://doi.org/10.1007/s10570-020-03295-3

Kabir SMF, Sikdar PP, Haque B, Bhuiyan MAR, Ali A, Islam MN (2018) Cellulose-based hydrogel materials: chemistry, properties and their prospective applications. Prog Biomater 7:153-174. https://doi.org/10.1007/s40204-018-0095-0

Liu H, Rong L, Wang B et al (2017) Facile fabrication of redox/pH dual stimuli responsive cellulose hydrogel. Carbohydr Polym 176:299-306. https://doi.org/10.1016/j.carbpol.2017.08.085

Liu Y, Sui Y, Liu C, Liu C, Wu M, Li B, Li Y (2018a) A physically crosslinked polydopamine/nanocellulose hydrogel as potential versatile vehicles for drug delivery and wound healing. Carbohydr Polym 188:27-36. https://doi.org/10.1016/j.carbpol.2018.01.093

Liu Y, Wang Q, Shen Q et al (2018b) Polydopamine/Cellulose Nanofibrils Composite Film as Potential Vehicle for Drug Delivery. ChemistrySelect 3:6852-6858. https://doi.org/10.1002/slct.201801118

Moharrami P, Motamedi E (2020) Application of cellulose nanocrystals prepared from agricultural wastes for synthesis of starch -based hydrogel nanocomposites: Efficient and selective nanoadsorbent for removal of cationic dyes from water. Bioresour Technol 313. https://doi.org/10.1016/j.biortech.2020.123661

Nigmatullin R, Gabrielli V, Munoz-Garcia JC et al (2019) Thermosensitive supramolecular and colloidal hydrogels via self-assembly modulated by hydrophobized cellulose nanocrystals. Cellulose 26:529-542. https://doi.org/10.1007/s10570-018-02225-8

Pabon-Pereira CP, Hamelers HVM, Matilla I, van Lier JB (2020) New Insights on the Estimation of the Anaerobic Biodegradability of Plant Material: Identifying Valuable Plants for Sustainable Energy Production. Processes 8. https://doi.org/10.3390/pr8070806

Pan Y, Liu J, Yang K, Cai P, Xiao H (2021) Novel multi-responsive and sugarcane bagasse cellulose-based nanogels for controllable release of doxorubicin hydrochloride. Mater Sci Eng C 118. https://doi.org/10.1016/j.msec.2020.111357 
Pan Y, Wang J, Cai P, Xiao H (2018) Dual-responsive IPN hydrogel based on sugarcane bagasse cellulose as drug carrier. Int J Biol Macromol 118:132-140. https://doi.org/10.1016/j.ijbiomac.2018.06.072

Pan Y, Zhao X, Li X, Cai P (2019) Green-Based Antimicrobial Hydrogels Prepared from Bagasse Cellulose as 3D-Scaffolds for Wound Dressing. Polymers 11. https://doi.org/10.3390/polym11111846

Pandey SK, Patel DK, Maurya AK et al (2016) Controlled release of drug and better bioavailability using poly(lactic acid-co-glycolic acid) nanoparticles. Int J Biol Macromol 89:99-110. https://doi.org/10.1016/j.ijbiomac.2016.04.065

Qiu X, Hu S (2013) "Smart" Materials Based on Cellulose: A Review of the Preparations, Properties, and Applications. Materials 6:738-781. https://doi.org/10.3390/ma6030738

Shen Y, Li X, Huang Y et al (2016) pH and Redox Dual Stimuli-Responsive Injectable Hydrogels Based on Carboxymethyl Cellulose Derivatives. Macromol Res 24:602-608. https://doi.org/10.1007/s13233-016-4077-6

Sun Y, Gao J, Liu Y, Kang H, Xie M, Wu F, Qiu H (2019) Copper sulfide-macroporous polyacrylamide hydrogel for solar steam generation. Chem Eng Sci 207:516-526. https://doi.org/10.1016/j.ces.2019.06.044

Thakur VK, Thakur MK (2015) Recent advances in green hydrogels from lignin: a review. Int J Biol Macromol 72:834-847. https://doi.org/10.1016/j.ijbiomac.2014.09.044

Thinkohkaew K, Rodthongkum N, Ummartyotin S (2020) Coconut husk (Cocos nucifera) cellulose reinforced poly vinyl alcohol-based hydrogel composite with control-release behavior of methylene blue. J Mater Res Technol 9:6602-6611. https://doi.org/ 10.1016/j.jmrt.2020.04.051

Van Soest PJ (1963) Use of detergents in the analysis of fibrous feeds. I. Preparation of fiber residues of low nitrogen content. J AOAC Int 46:825-829. https://doi.org/10.1093/jaoac/46.5.825

Van Soest PJ, Jones LHP (1968) Effect of silica in forages upon digestibility. J Dairy Sci 51:1644-1648. https://doi.org/10.3168/jds.S0022-0302(68)87246-7

Wang C, Fadeev M, Zhang J, Vazquez-Gonzalez M, Davidson-Rozenfeld G, Tian H, Willner I (2018) Shape-memory and self-healing functions of DNA-based carboxymethyl cellulose hydrogels driven by chemical or light triggers. Chem Sci 9:7145-7152. https://doi.org/10.1039/c8sc02411a

Wang F, Pan Y, Cai P, Guo T, Xiao H (2017) Single and binary adsorption of heavy metal ions from aqueous solutions using sugarcane cellulose-based adsorbent. Bioresour Technol 241:482-490. https://doi.org/10.1016/j.biortech.2017.05.162

Wang F, Zhang Q, Li X, Huang K, Shao W, Yao D, Huang C (2019a) Redox-responsive blend hydrogel films based on carboxymethyl cellulose/chitosan microspheres as dual delivery carrier. Int J Biol 
552 Wang Y, Xiao G, Peng Y, Chen L, Fu S (2019b) Effects of cellulose nanofibrils on dialdehyde 553 carboxymethyl cellulose based dual responsive self-healing hydrogel. Cellulose 26:8813-8827. 554 https://doi.org/10.1007/s10570-019-02673-w

555 Wei Z, Yang J, Zhou J et al (2014) Self-healing gels based on constitutional dynamic chemistry and their 556 potential applications. Chem Soc Rev 43:8114-8131. https://doi.org/10.1039/c4cs00219a 

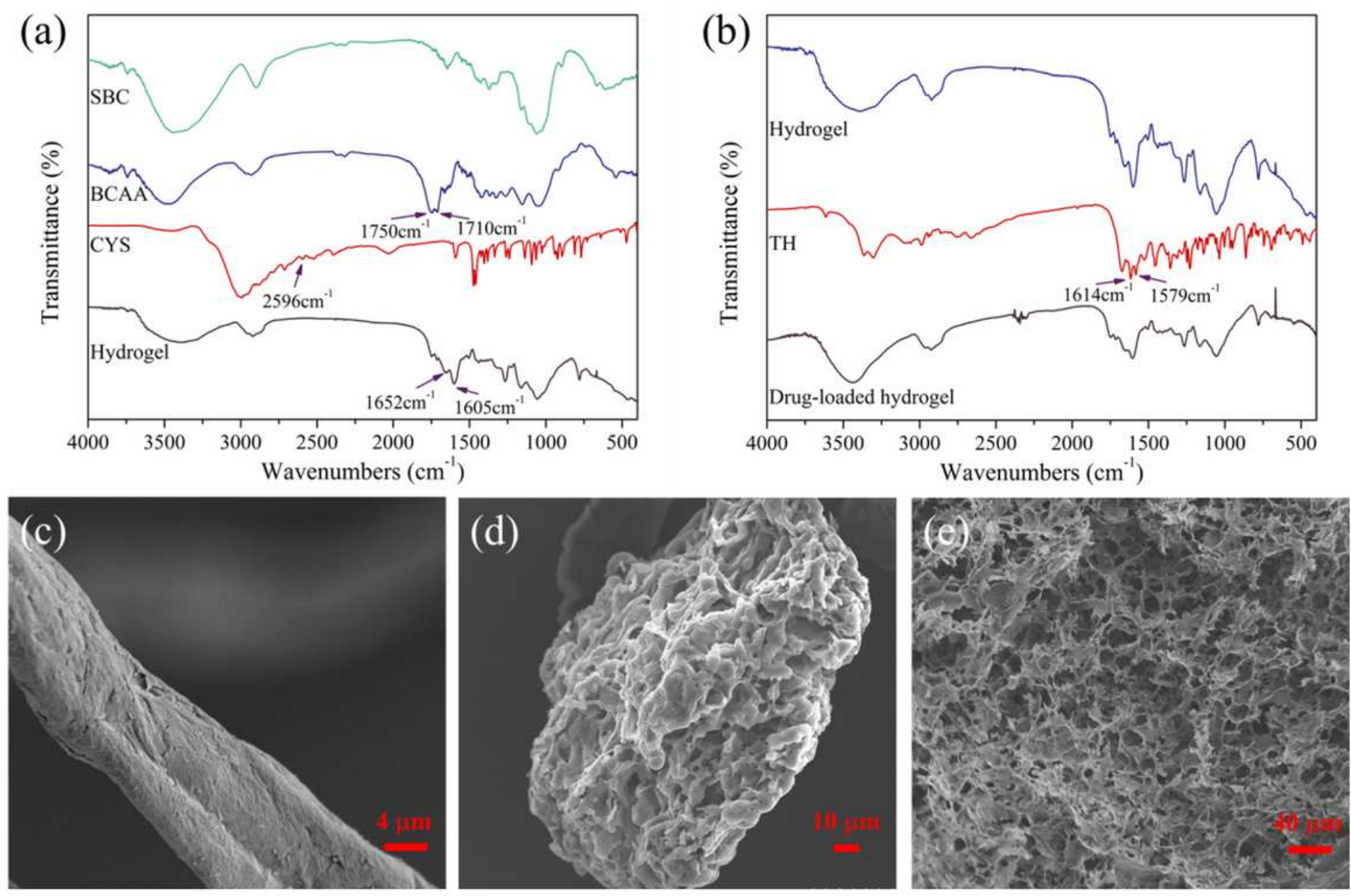

\section{Figure 1}

(a) FTIR spectra of SBC, BCAA, CYS and Hydrogel, (b) FTIR spectra of Hydrogel, TH and Drug-loaded hydrogel, SEM images of SBC (c), BCAA (d) and hydrogel (e)

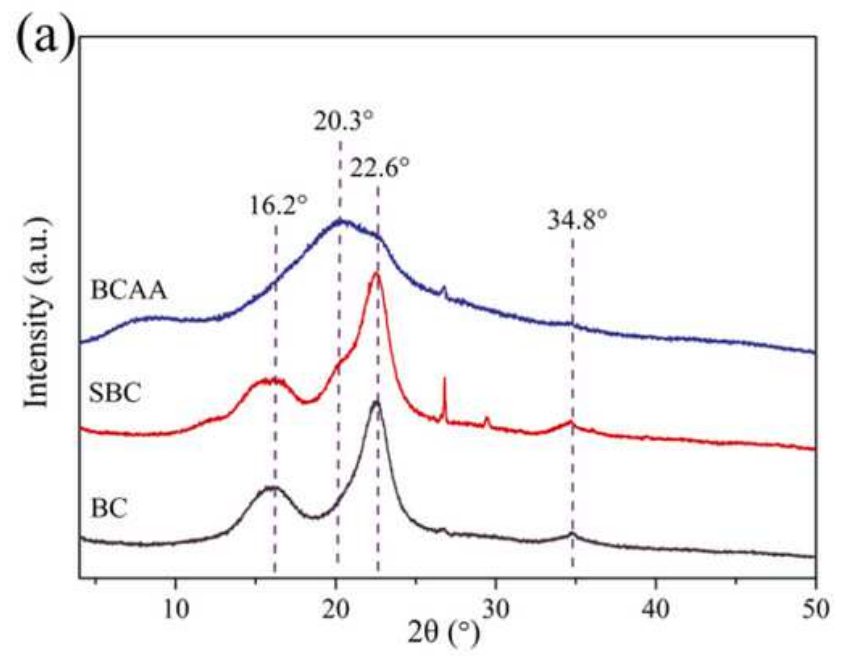

(b)
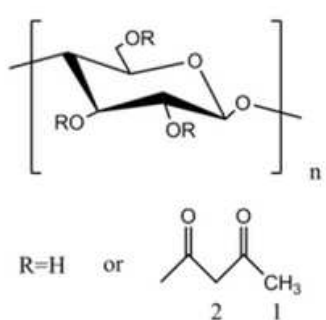

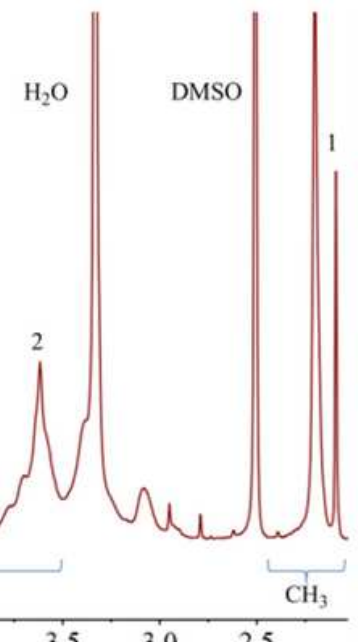

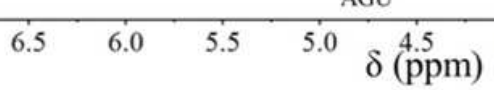


Figure 2

(a) XRD of BC, SBC and BCAA, (b) 1 H NMR of BCAA

(a)
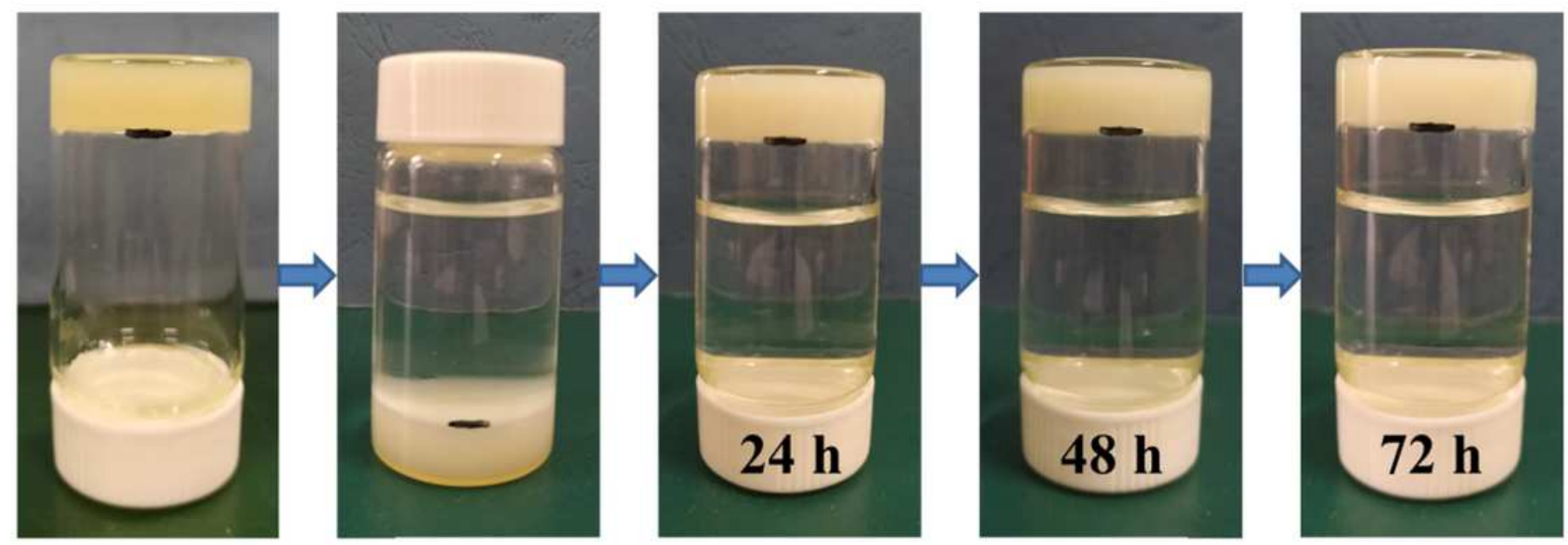

(b)

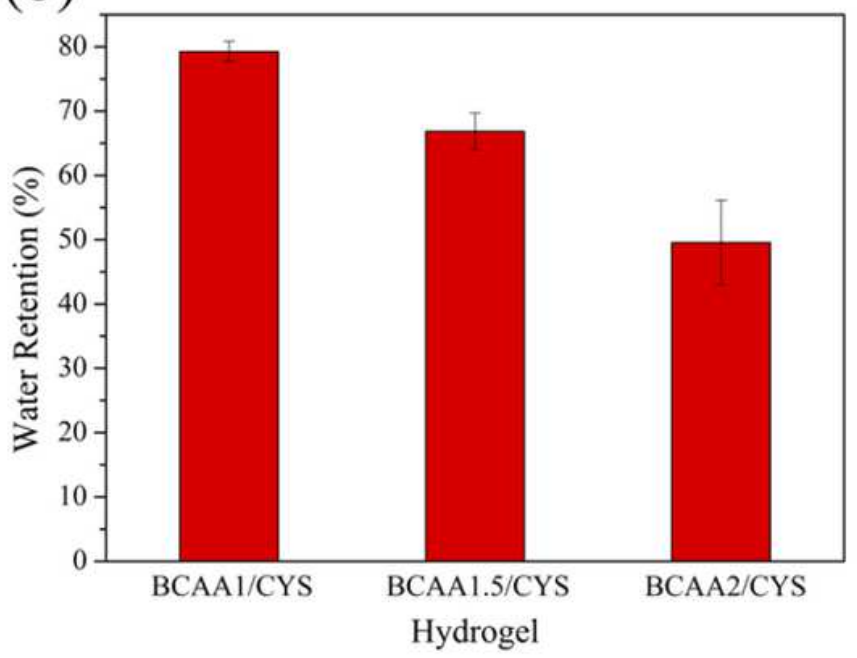

Figure 3

(a) Stability of cellulose hydrogel in PBS solution ( $24 \mathrm{~h}, 48 \mathrm{~h}, 72 \mathrm{~h}$ ), (b) water retention of different hydrogels 
(a)

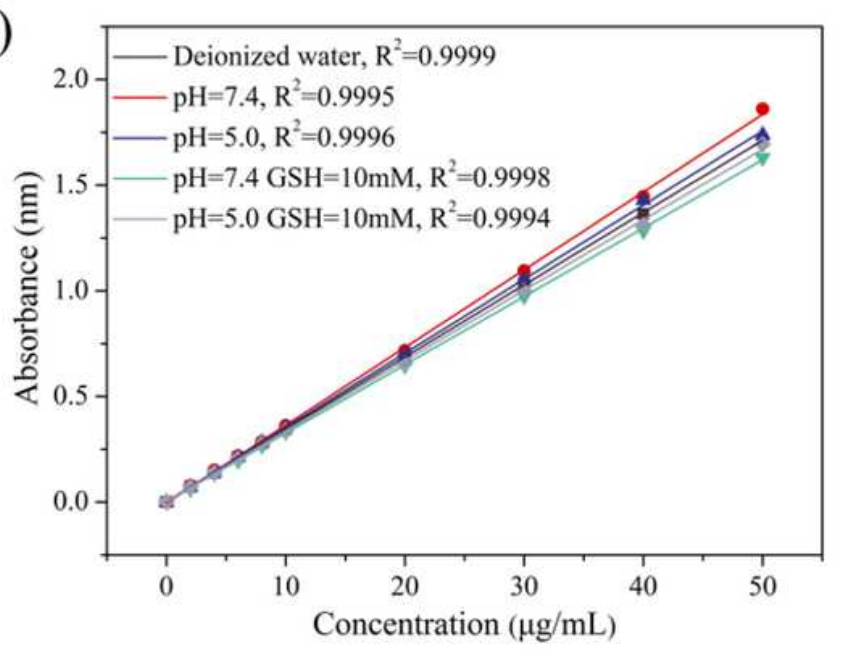

(c)

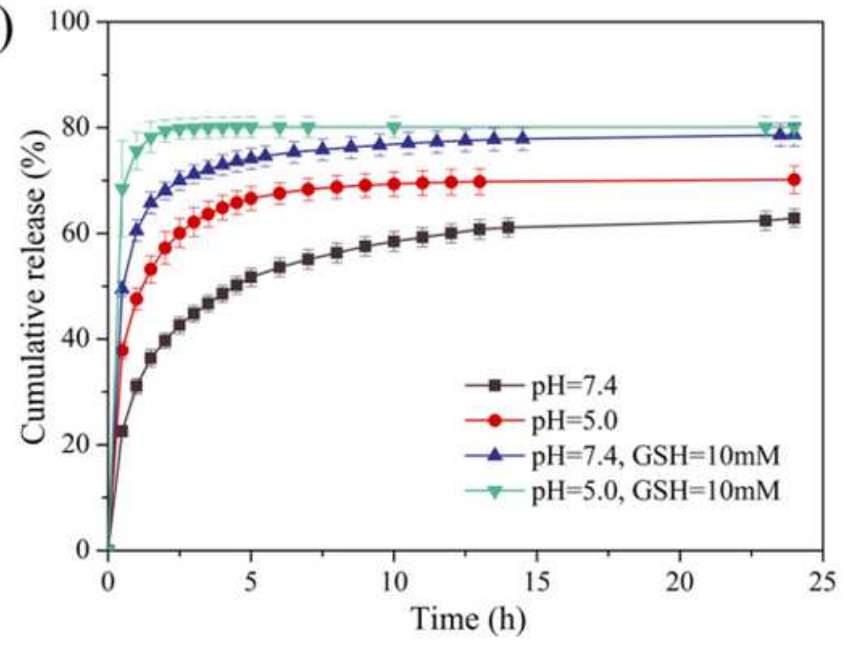

(b)

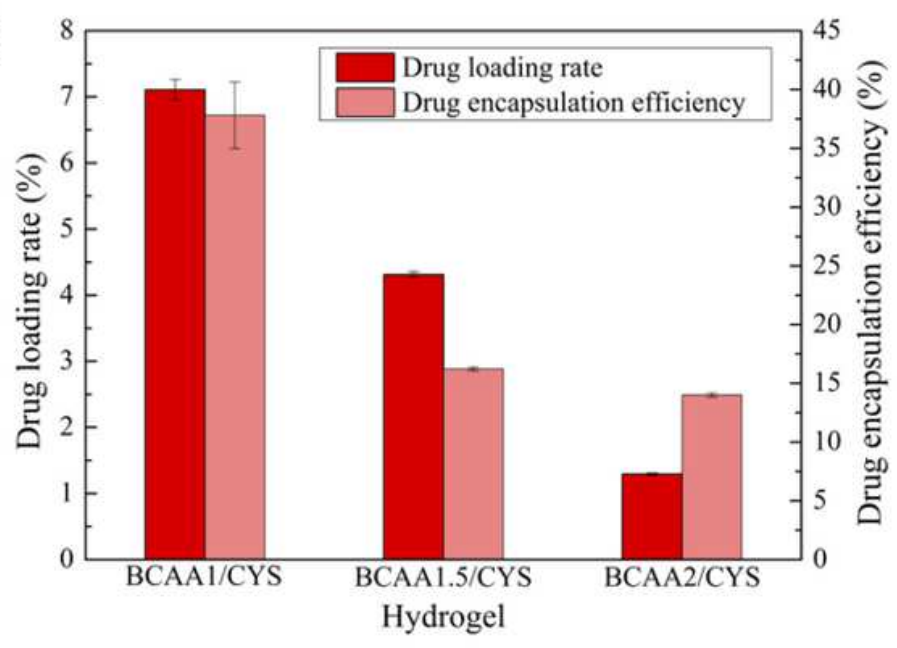

(d)

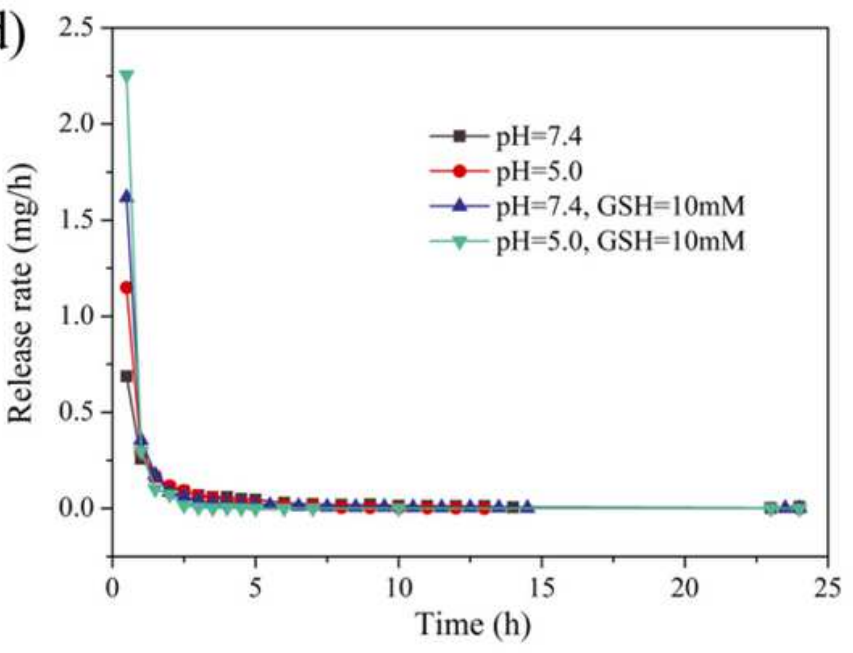

\section{Figure 4}

(a) Standard curve of TH in different slow-release environments, (b) the drug loading rate and encapsulation efficiency of different hydrogels for $\mathrm{TH}$, (c) the cumulative release of drug-loaded hydrogels under different conditions $(\mathrm{pH}=7.4, \mathrm{pH}=5.0, \mathrm{pH}=7.4$ with $10 \mathrm{mM} \mathrm{GSH}$, and $\mathrm{pH}=5.0$ with 10 $\mathrm{mM} \mathrm{GSH}$, respectively), (d) the release rates versus time at different conditions $(\mathrm{pH}=7.4, \mathrm{pH}=5.0, \mathrm{pH}=$ 7.4 with $10 \mathrm{mM} \mathrm{GSH}$, and $\mathrm{pH}=5.0$ with $10 \mathrm{mM} \mathrm{GSH}$, respectively)
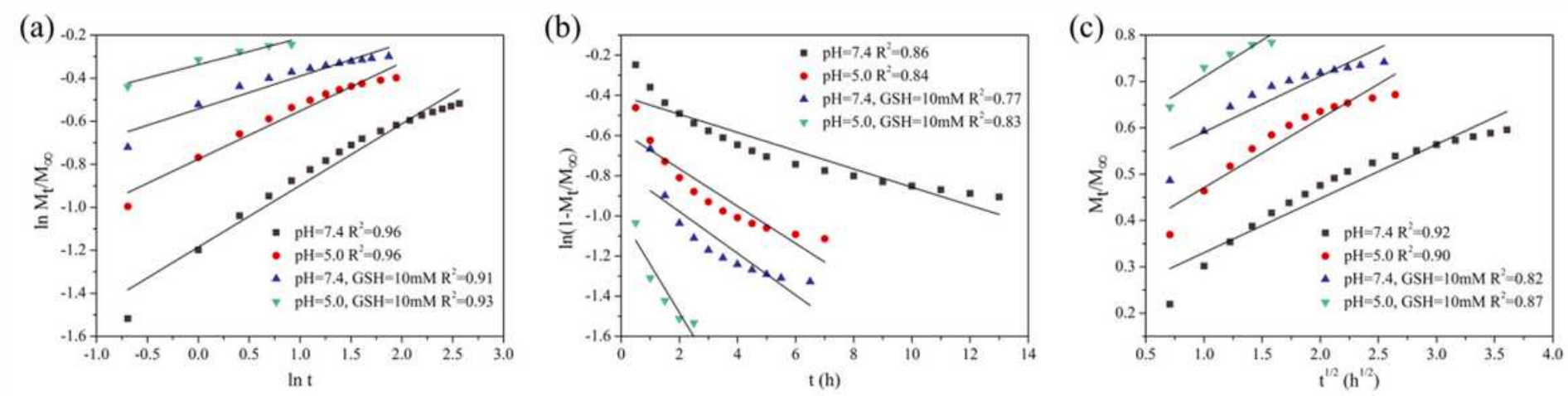
(a) Plot of $\ln (\mathrm{Mt} / \mathrm{M} \infty)$ versus Int for the release of TH from BCAA/CYS hydrogel in different release conditions $(\mathrm{pH}=7.4, \mathrm{pH}=5.0, \mathrm{pH}=7.4$ with $10 \mathrm{mM} \mathrm{GSH}$, and $\mathrm{pH}=5.0$ with $10 \mathrm{mM} \mathrm{GSH}$, respectively), (b) plot of $\ln (1-\mathrm{Mt} / \mathrm{M} \infty)$ versus $t$ for the release of TH from BCAA/CYS hydrogel in different release conditions $(\mathrm{pH}=7.4, \mathrm{pH}=5.0, \mathrm{pH}=7.4$ with $10 \mathrm{mM} \mathrm{GSH}$, and $\mathrm{pH}=5.0$ with $10 \mathrm{mM} \mathrm{GSH}$, respectively), (c) plot of $\mathrm{Mt} / \mathrm{M} \infty$ versus $\mathrm{t} 1 / 2$ for the release of $\mathrm{TH}$ from BCAA/CYS hydrogel in different release conditions $(\mathrm{pH}=$ $7.4, \mathrm{pH}=5.0, \mathrm{pH}=7.4$ with $10 \mathrm{mM} \mathrm{GSH}$, and $\mathrm{pH}=5.0$ with $10 \mathrm{mM} \mathrm{GSH}$, respectively)
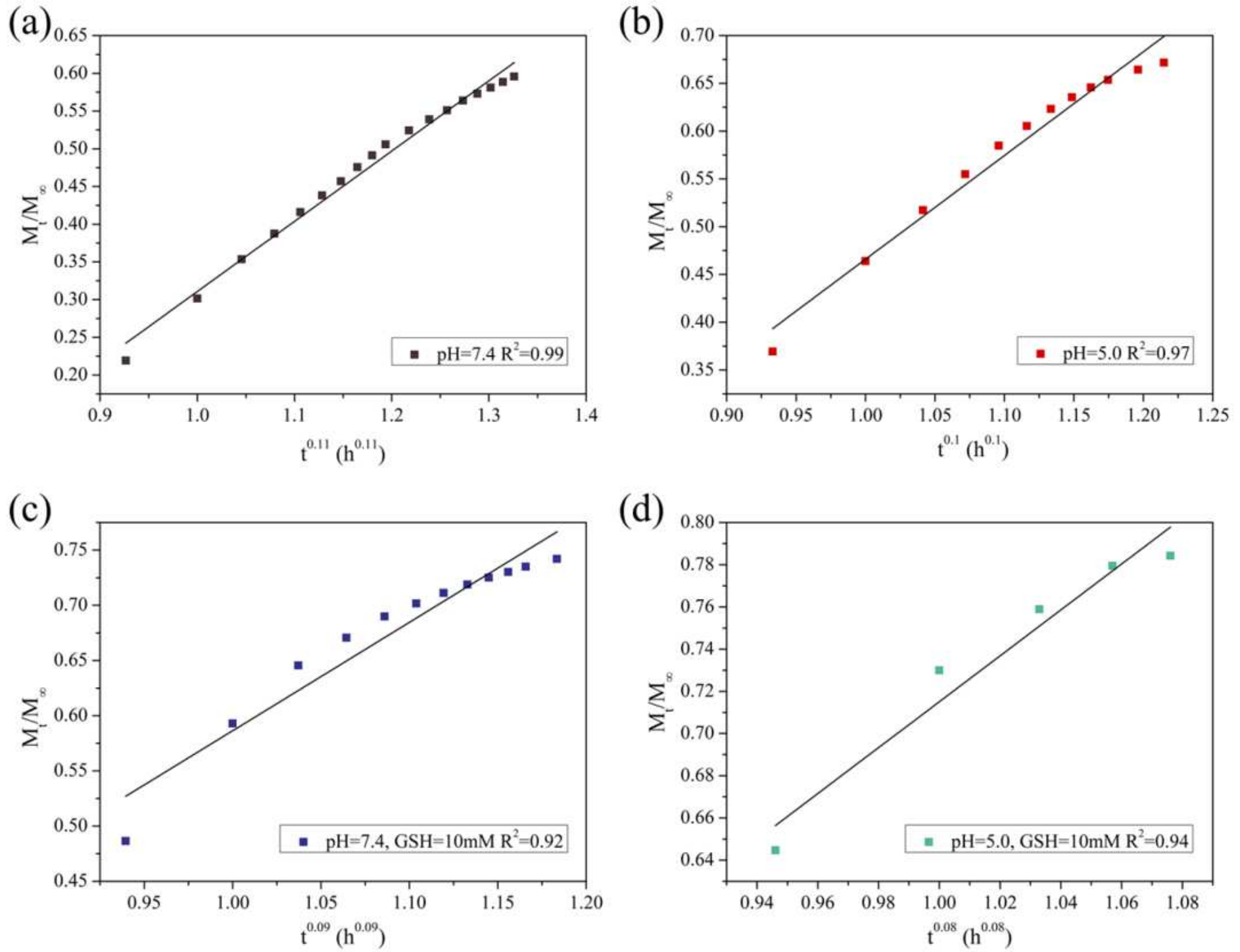

\section{Figure 6}

Plot of $\mathrm{Mt} / \mathrm{M} \infty$ versus tn for the release of TH from BCAA/CYS hydrogel $(a, b, c$, and $d, n=0.11,0.1,0.09$, 0.08 , respectively) in different release conditions $(\mathrm{pH}=7.4, \mathrm{pH}=5.0, \mathrm{pH}=7.4$ with $10 \mathrm{mM} \mathrm{GSH}$, and $\mathrm{pH}=$ 5.0 with $10 \mathrm{mM} \mathrm{GSH}$, respectively) 


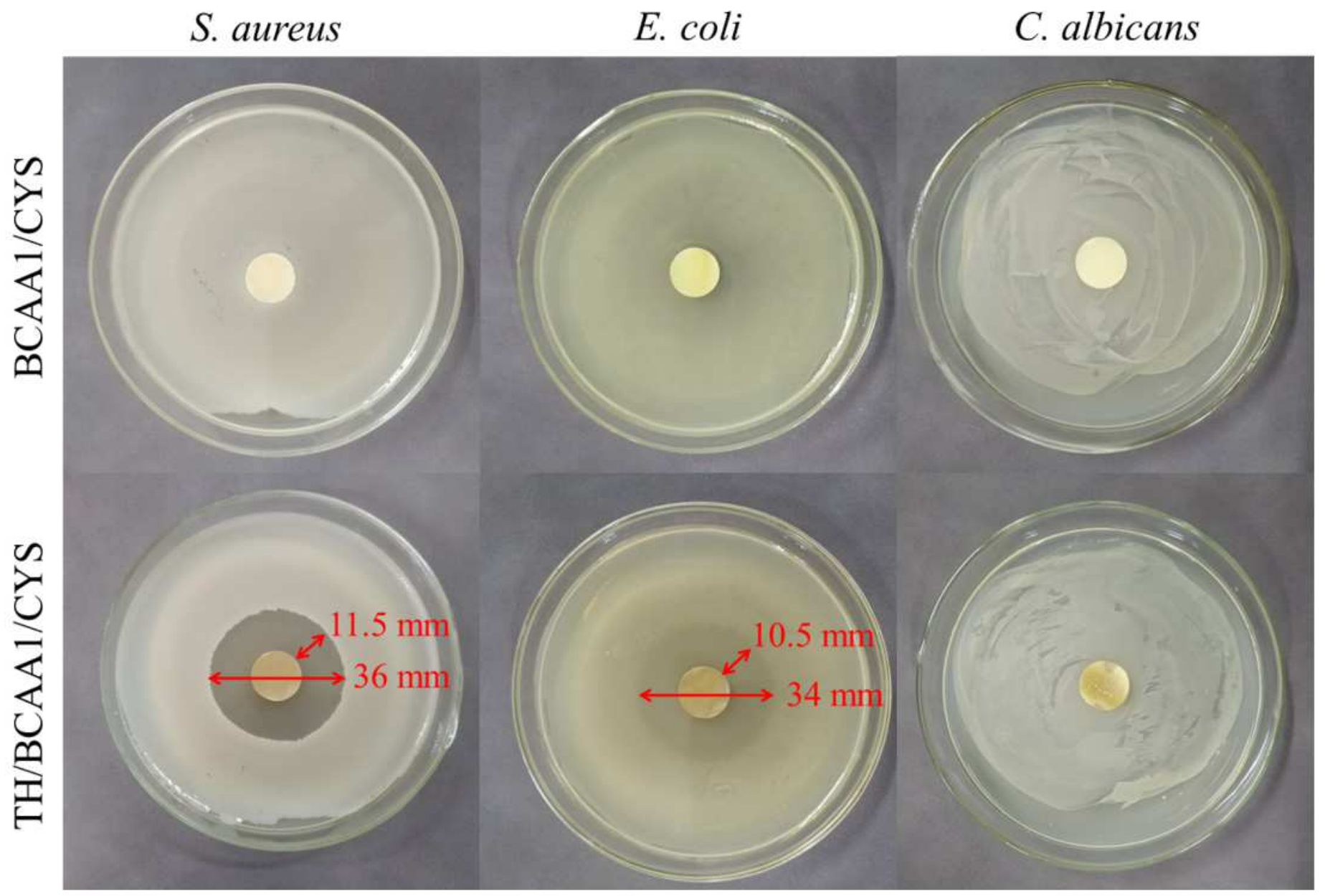

Figure 7

The inhibition zone test of hydrogels (BCAA1/CYS and TH/BCAA1/CYS) against S. aureus, E. coli and C. albicans
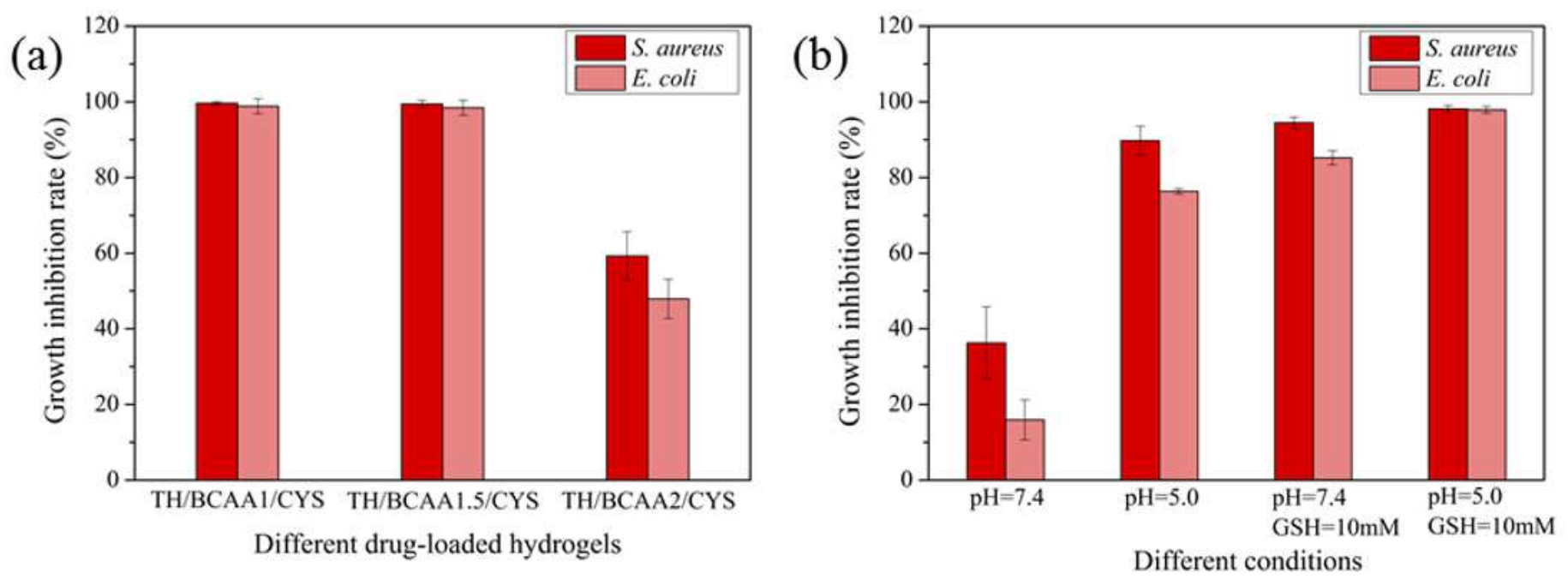

Figure 8 
(a) The growth inhibition rate of different drug-loaded hydrogels against $\mathrm{S}$. aureus and $\mathrm{E}$. coli, (b) the growth inhibition rate of TH/BCAA1/CYS hydrogel against $\mathrm{S}$. aureus and E. coli within $4 \mathrm{~h}$ under different conditions $(\mathrm{pH}=7.4, \mathrm{pH}=5.0, \mathrm{pH}=7.4$ with $10 \mathrm{mM} \mathrm{GSH}$, and $\mathrm{pH}=5.0$ with $10 \mathrm{mM} \mathrm{GSH}$, respectively) 